Luiz Pacheco Drumond Neto

Revisão dos Processos Logísticos Intra Hospitalares de

Medicamentos - Unitarização e Dispensação

Dissertação de Mestrado

Dissertação apresentada como requisito parcial para obtenção do título de Mestre (opção profissional) pelo programa de Pós-Graduação em Engenharia de Produção da PUC-Rio.

Orientador: Prof. Silvio Hamacher 


\title{
REVISÃO DOS PROCESSOS LOGÍSTICOS INTRA HOSPITALARES DE MEDICAMENTOS - UNITARIZAÇÃO E DISPENSAÇÃO
}

\begin{abstract}
Dissertação apresentada como requisito parcial para obtenção do título de Mestre (opção profissional) pelo programa de Pós-Graduação em Engenharia de Produção da PUC-Rio. Aprovada pela Comissão Examinadora abaixo assinada.
\end{abstract}

Prof. Silvio Hamacher

Orientador

Departamento de Engenharia Industrial - PUC-Rio

Prof. Luiz Felipe Roris Rodrigues Scavarda do Carmo

Departamento de Engenharia Industrial - PUC-Rio

Dra. Aline Silva de Medeiros, Dra.

AMIL

Prof. José Eugênio Leal

Coordenador Setorial do Centro Técnico Científico - PUC-Rio

Rio de Janeiro, 26 de fevereiro de 2015. 
Todos os direitos reservados. É proibida a reprodução total ou parcial do trabalho sem autorização da universidade, do autor e do orientador.

\section{Luiz Pacheco Drumond Neto}

Engenheiro de Produção graduado na Pontifícia Universidade Católica do Rio de Janeiro (PUC-Rio) fez um curso de extensão em Gestão de Investimento e Valoração de Empresas na Pontifícia Universidade Católica do Rio de Janeiro (Rio de Janeiro, Brasil). Desenvolveu junto com o seu orientador durante o Mestrado um trabalho de revisão dos processos logísticos hospitalares de unitarização e dispensação. Teve passagem profissional pela área de Planejamento Estratégico de Metais Básicos, na Vale. Atua hoje como consultor de Supply Chain na EY.

Ficha Catalográfica

Drumond Neto, Luiz Pacheco

Revisão dos processos logísticos intra hospitalares de medicamentos: unitarização e dispensação / Luiz Pacheco Drumond Neto; orientador: Silvio Hamacher. - 2015.

83 f. : il. (color.) ; $30 \mathrm{~cm}$

Dissertação (mestrado)-Pontifícia Universidade Católica do Rio de Janeiro, Departamento de Engenharia Industrial, 2015.

Inclui bibliografia

1. Engenharia Industrial - Teses. 2. Unitarização. 3. Dispensação. 4. Farmácia Hospitalar. 5. Logística Interna. 6. Medicamentos. I. Hamacher, Silvio. II. Pontifícia Universidade Católica do Rio de Janeiro. Departamento de Engenharia Industrial. III. Título. 
Aos meus pais, Elizabeth Christina e Luiz Antônio, principais responsáveis pela minha educação. 


\section{Agradecimentos}

Agradeço, primeiramente, a Deus por me dar a oportunidade que tanto batalhei e me guiar durante esses anos de mestrado para que se tornasse real um sonho pessoal e profissional. Mais uma etapa se encerra e muitas outras virão. Que Ele sempre me acompanhe e ilumine meu caminho, me proporcionando sabedoria, saúde e força para seguir em frente e para que eu possa ser uma pessoa e um profissional digno e honrado.

Gostaria de agradecer também aos meus pais, Luiz Antônio Lourenço Drumond e Elizabeth Christina Dutra Gama, pelo apoio que eles me deram nas horas mais difíceis, por toda a compreensão que eles tiveram durante esses dois anos de estudo, além desses últimos meses que foram bastante complicados principalmente pela conclusão da dissertação.

Agradeço a minha namorada, Juliana Pires Curty por ter me ajudado bastante durante esse tempo que dediquei escrevendo este trabalho e sempre me incentivado a escrever mesmo quando estávamos viajando a lazer. Não posso deixar de citar a sua mãe, Fernanda Curty Pires, seu pai, Carlos Roberto Curty Abreu por terem me ajudado durante o processo de busca por uma organização hospitalar onde eu pudesse desenvolver o meu estudo de caso.

Agradeço ao professor Silvio Hamacher pela orientação e ajuda durante todas as etapas de desenvolvimento do trabalho, desde a ideia inicial até o dia da apresentação final. Seu entusiasmo me motivou a "suar a camisa" e buscar os melhores resultados.

Ao professor Luiz Felipe Scavarda, obrigado pelo incentivo em continuar o estudo do tema Logística Hospitalar, visto que cheguei a pensar em escrever sobre outros assuntos com medo de que não pudesse fazer uma dissertação sólida e com um bom estudo de caso.

Não posso deixar de agradecer também ao médico Doutor Carlos Alberto da Silva, que me foi indicado pela família da minha namorada e que fez essa ponte entre eu e o hospital onde foi realizado o trabalho.

Por fim, não posso deixar de agradecer aos profissionais que participaram das entrevistas, falando em nome das suas organizações. Fiquei impressionado e imensamente agradecido com o excelente tratamento que recebi durante a realização das visitas e com o interesse despendido pelos entrevistados. 


\section{Resumo}

Drumond Neto, Luiz Pacheco; Hamacher, Sílvio (Orientador). Revisão dos Processos Logísticos Intra Hospitalares de Medicamentos Unitarização e Dispensação. Rio de Janeiro, 2015. 83p. Dissertação de Mestrado - Departamento de Engenharia Industrial, Pontifícia Universidade Católica do Rio de Janeiro.

Em organizações hospitalares há uma grande variedade de produtos e existe o compromisso de não se permitir as perdas e o fracasso operacional (Portela, 2001). Uma maneira de se evitar essas perdas é o emprego racional dos medicamentos através de uma padronização (Klügl et al, 1999). Desse modo é possível criar valor ao paciente de modo que a farmácia consegue administrar os produtos de forma adequada oferecendo serviços de qualidade (Barbieri e Machline, 2006). Nesse cenário, a gestão dos custos das organizações de saúde tem papel estratégico. Medicamentos representam parcela significativa destes custos e a sua logística interna, complexa e com muitas particularidades, deve funcionar da melhor maneira possível. Isso porque os processos, nos quais estão envolvidos, são parte fundamental para a assistência de qualidade tanto prezada pelos hospitais. Este trabalho tem como objetivo investigar e analisar a situação atual de dois processos, unitarização e a dispensação que afetam diretamente a farmácia, observando as práticas, adotadas no segmento hospitalar. Para isto, foi feito uma análise das farmácias hospitalares e dos fluxos de ambos os processos com o objetivo de entendê-los melhor. Em seguida, estudou-se em um caso real, diagnosticando os pontos de melhoria da operação. Assim, pôde-se chegar a algumas soluções, que tiveram como objetivo otimizar os processos estudados, para os pontos de melhoria levantados e comprovar a hipótese de que a centralização do estoque pode ser aplicados, com devidas adaptações respeitando as particularidades, às organizações hospitalares.

\section{Palavras-chave}

Unitarização; Dispensação; Farmácia Hospitalar; Logística Interna; Medicamentos. 


\section{Abstract}

Drumond Neto, Luiz Pacheco; Hamacher, Sílvio (Orientador). Review of Intra Hospital Drugs Logistics Process - Unitization and Dispensation. Rio de Janeiro, 2015. 83p. MSc. Dissertation - Departamento de Engenharia Industrial, Pontifícia Universidade Católica do Rio de Janeiro.

In hospital organizations there is a wide variety of products and there is a commitment not to allow the losses and the operational failure (Portela, 2001). One way to avoid these losses is the rational use of medicines through standardization (Klügl et al, 1999). Thus you can create value to the patient so that the pharmacy handling the products properly offering quality services (Barbieri and Machline, 2006). In this scenario, the management of the health costs organizations have strategic role. Medicines represent a significant portion of these costs and their internal logistics, complex and with many details, should work in the best possible way. This is because the processes, in which they are involved, are fundamental parts to the quality of care both prized by hospitals. This study aims to investigate and analyze the current situation of two processes, unitarization and the dispensation that directly affect the pharmacy, observing the practices adopted in the hospital segment. For this, he was made an analysis of hospital pharmacies and flows of both processes in order to understand them better. Then studied in a real case, diagnosing the points of improvement of the operation. Thus, we could come up with some solutions that were designed to optimize the processes studied for improvement points raised and prove the hypothesis that the stock of centralization can be applied, with necessary adaptations respecting the individual, to hospitals.

\section{Keywords}

Unitarization; Dispensation; Hospital Pharmacy; Internal Logistics; Medicines. 


\section{Sumário}

1. INTRODUÇÃO

2. FUNDAMENTAÇÃO TEÓRICA

2.1. GeSTÃo de SAÚde 14

2.2. CARACTERIZAÇÃO DOS HOSPITAIS

2.3. TAXONOMIA 18

2.4. LOGÍSTICA INTERNA DE MEDICAMENTOS 22

2.4.1. UNITARIZAÇÃO DE MEDICAMENTOS 24

2.4.2. DISPENSAÇÃO 27

2.5. GeSTÃo DO EstOQUE 28

3. PANORAMA DA SAÚDE NO BRASIL 31

4. PESQUISA DE CAMPO 39

4.1. Metodologia e Desenho da Pesquisa 39

4.2. ESCOLHA DA ORGANIZAÇ̃̃O 41

4.3. HOSPITAL SELECIONADO 44

5. ESTUDO DE CASO: ESTADO ATUAL 46

5.1. FARMÁCIA CENTRAL 46

5.2. FLUXO DE INFORMAÇÃO

5.3. UNITARIZAÇÃO 49

5.4. DISPENSAÇÃO

5.4.1. DISPENSAÇÃO PARA A UTI 52

5.4.2. DISPENSAÇÃO PARA OS LEITOS 54

5.4.3. LOGÍSTICA REVERSA DA DISPENSAÇÃO

5.4.4. DiAGNÓSTICO DA DISPENSAÇÃO

6. ESTUDO DE CASO: MELHORIAS PROPOSTAS 57

6.1. FLUXO DE INFORMAÇÃO

6.2. UNITARIZAÇÃO

6.3. DISPENSAÇÃO

7. CONCLUSÃO

REFERÊNCIAS BIBLIOGRÁFICAS

APÊNDICE I 


\section{Lista de figuras}

$\begin{array}{ll}\text { Figura 1: Novas tecnologias na saúde. } & 15\end{array}$

$\begin{array}{ll}\text { Figura 2: Pirâmide etária brasileira. } & 16\end{array}$

Figura 3: Níveis hierárquicos e administrativos. 20

$\begin{array}{ll}\text { Figura 4: Serviços e níveis hierárquicos. } & 21\end{array}$

Figura 5: Processos do fluxo de medicamentos. 22

Figura 6: Exemplo de fluxo de medicamentos e materiais hospitalares dentro

de hospitais. 23

Figura 7: Alta complexidade das características operacionais dos insumos médicohospitalares. 24

Figura 8: Embalagem primária fracionável. 25

Figura 9: Quantidade de hospitais. 31

Figura 10: Radiografia dos leitos hospitalares.

Figura 11: Quantidade de leitos SUS. 32

Figura 12: Quantidade de leitos não SUS. 33

Figura 13: Leitos para internação por mil habitantes. 34

Figura 14: Receitas de contraprestações.

Figura 15: Faturamento hospitais ANAHP. 35

Figura 16: Número de beneficiários de planos de saúde. 35

Figura 17: Total de internações. 36

Figura 18: Distribuição da receita por tipo. 36

Figura 19: Despesas assistenciais. $\quad 37$

Figura 20: Distribuição das despesas nos hospitais ANAHP. 37

Figura 21: Medicamento unitarizado armazenado. $\quad 46$

$\begin{array}{ll}\text { Figura 22: Planta da farmácia central. } & 47\end{array}$

Figura 23: Fluxo de informações. 48

Figura 24: Política de reposição de estoque. 50

Figura 25: Itens utilizados no processo de dispensação. 53

Figura 26: Novo fluxo de informações. $\quad 58$

Figura 27: Novo processo de reposição de estoque. $\quad 59$ 


\section{Lista de tabelas}

$\begin{array}{lr}\text { Tabela } 1 \text { Classificação dos hospitais gerais por porte. } & 18\end{array}$

Tabela 2: Critérios para a escolha do objeto de pesquisa. 43

Tabela 3: Tabela de quantidade de medicamentos unitarizados por local e tipo. $\quad 62$

Tabela 4: Tabela de setups e tempo por tipos e quantidades para o processo atual. $\quad 64$

Tabela 5: Tabela de quantidade de medicamentos unitarizados por tipo. 65

Tabela 6: Tabela de setups e tempo por tipos e quantidades para o processo proposto. 66 


\section{Introdução}

Medicamentos são insumos básicos à vida. Um estudo publicado no boletim Morbidity and Mortality Weekly Report (2006), mostra que aproximadamente $50 \%$ das mulheres e $40 \%$ dos homens entrevistados informaram a utilização de algum medicamento no mês anterior ao estudo, excluindo as situações de automedicação.

Os insumos hospitalares, dentre eles os medicamentos, além de representar o maior percentual da receita de um hospital (47,9\%), também são responsáveis pela segunda maior despesa $(25,2 \%)$ (Observatório ANHAP, 2013).

Conforme afirmado por Barbieri e Machline (2006) é difícil estabelecer a real necessidade de medicamentos quando o paciente é admitido na instituição, o que gera a necessidade de formação dos estoques de remédios da farmácia hospitalar.

Sendo assim, a finalidade da farmácia hospitalar é garantir a qualidade da assistência prestada ao paciente, através do uso seguro e racional de medicamentos, adequando sua aplicação à saúde individual e coletiva (Cavallini e Bisson, 2002).

Fitzsimmons e Fitzsimmons (2005), afirmam que a principal dificuldade na logística hospitalar consiste em manter o estoque disponível na mesma proporção da demanda, objetivando a redução de custos, já que todo e qualquer armazenamento de materiais gera custos (Arozo, 2002)

Além disso, o aumento da média de idade de vida da população nos últimos anos, aliado a uma mudança nos hábitos, ocasionou o surgimento de novas doenças, a necessidade de novos exames e maiores cuidados na saúde.

Logo, a busca por exames cada vez mais modernos fez com que os hospitais tivessem que se adaptar através da compra de equipamentos novos e mais caros. Esse gasto com equipamentos, além dos desperdícios e furtos de medicamentos, fez com que os custos nos hospitais ficassem cada vez maiores. E em um setor caracterizado por sucessivas restrições de orçamento, o controle de recursos deve aliar-se à sua utilização eficiente, uma vez que todo cidadão utilizará o serviço 
prestado por uma instituição de saúde, a nível hospitalar ou ambulatorial, durante seu ciclo de vida e para manter sua saúde (Cavallini e Bisson, 2002).

Desse modo, os hospitais estão buscando aperfeiçoar os seus processos, para assim criar valor ao paciente e melhorar a qualidade do atendimento.

Outro fator importante nesse segmento é o fato dos hospitais em sua maioria serem comandados por médicos ou por gestão familiar. Nesse caso, a falta de visão da importância da logística nas organizações acaba fazendo com que muitos problemas relacionados à operação logística do hospital não sejam solucionados ou mesmo identificados.

Após observar todos os fatores expostos acima, entende-se que a farmácia é um local importante, pois é neste local que ocorre diversos processos que impactam diretamente a logística interna do hospital.

Assim, este trabalho tem como objetivo estudar a logística interna hospitalar de medicamentos, mais especificamente dois processos que ocorrem dentro da farmácia e têm grande impacto na cadeia de suprimentos do hospital: a unitarização e a dispensação e propor um novo modelo para ambos os processos de forma que estes sejam otimizados.

Buscando uma melhor organização da pesquisa, este estudo está organizado em sete capítulos, com o primeiro sendo a introdução.

No segundo capítulo, é a fundamentação teórica onde será caracterizada a gestão da saúde, os processos a serem estudados e a gestão de estoque através da revisão da literatura.

O terceiro capítulo é dedicado ao panorama atual da gestão de saúde no país bem como a situação dos hospitais.

O quarto capítulo busca explicar a metodologia utilizada para as análises de cada um dos processos passando para a escolha da organização hospitalar e o desenho da pesquisa.

No quinto capítulo a metodologia de trabalho é utilizada, buscando, primeiro, se entender o fluxo, a organização e o funcionamento tanto do processo de unitarização e dispensação dos medicamentos no hospital a ser analisado. Esse entendimento foi feito através de observações e entrevistas realizadas com os funcionários do hospital.

No sexto capítulo serão propostos novos modelos para os processos estudados. Para o processo de unitarização será proposto um novo modelo 
baseado em práticas de outros segmentos industriais, nas entrevistas realizadas e nas observações feitas. Após será realizada uma compilação das informações dos medicamentos unitarizados pelo hospital durante uma semana. Os dados serão tratados de modo que se possa quantificar e comparar os dois modelos e identificar os ganhos do novo modelo em relação ao modelo de unitarização praticado atualmente pelo hospital.

Para o processo de dispensação serão analisados os resultados das entrevistas com os diversos funcionários entrevistados e analisadas as observações em relação ao processo para que possa se propor algumas melhorias que possam vir a trazer benefícios reais.

Por fim, no sétimo e último capítulo faz uma conclusão dessa dissertação e recomendam-se trabalhos futuros. 


\section{Fundamentação Teórica}

Este capítulo foi desenvolvido com o objetivo de justificar o estudo e conhecer o que já foi publicado por outros autores sobre o tema, logística hospitalar.

Para isto o capítulo começa com um panorama da Gestão da Saúde, procurando entender os fatores que levam aos grandes gastos que acontecem no setor. Posteriormente é feito uma caracterização dos tipos de hospitais que existem e as suas classificações dos mesmos no Brasil.

Feito isso procurou-se entender como é uma organização hospitalar, suas diversas áreas. As hierarquias que existem dentro de um hospital. Por fim entra-se no tema da logística hospitalar, procurando entender os processos que existem dentro dela e focando nos dois processos que irão ser estudados nesse trabalho, a unitarização e a dispensação de medicamentos.

\subsection{Gestão de Saúde}

Nos últimos anos, a economia vem sofrendo mudanças importantes. As empresas atuantes no mercado estão buscando melhorar a sua competitividade devido a globalização cada vez mais acentuada. Essa é percebida em todos os setores da economia, cada qual no seu tempo, velocidade e intensidade e dentro do setor de saúde não é diferente.

Desse modo, com as mudanças que vem acontecendo no mundo, os hospitais estão sentindo a necessidade de se atualizarem também e se tornarem mais eficientes e eficazes em sua logística interna para não perder competitividade em relação aos seus concorrentes e minimizar os custos existentes, que são altos.

Assim, a gestão do complexo sistema de saúde chamou a atenção de diversos estudiosos. Porter e Teisberg (2006) argumentam que a combinação de altos custos dos serviços de saúde, qualidade insatisfatória do serviço e acesso limitado à assistência médica são responsáveis pela ansiedade e frustração dos participantes do sistema. Isso porque acabam afetando: 
- Empregadores - arcam com planos médicos onerosos e com funcionários insatisfeitos;

- Médicos e demais prestadores de serviço de saúde - recebem rendimentos reduzidos e têm seus dias de trabalho sobrecarregados de tarefas burocráticas;

- Planos de saúde - são criticados por reduzir o reembolso dos serviços prestados e por negar pedidos solicitados pelos médicos;

- Fornecedores de medicamentos e equipamentos - são acusados de provocar a elevação dos custos, em função do lançamento de terapias avançadas e onerosas, sem preocupações de incluir um espectro mais amplo de perfil econômico do público-alvo;

- Governos - acusados de ineficiência de gestão.

Em Porter e Teisberg (2006) é relatado que, nos Estados Unidos, em 2007 projeta-se gastar quase US\$ 2 trilhões anuais com assistência da saúde, aproximadamente $14 \%$ do PIB. Já no Brasil, dados disponibilizados pelo Ministérios da Saúde (SIOPS, 2011) mostram que os gastos correspondem a R\$ 320 bilhões por ano, ou 10\% do PIB brasileiro. Deste valor, o setor público é responsável por aproximadamente $\mathrm{R} \$ 140$ bilhões por ano, ou então 44\%, já o setor privado é responsável pelos outros $56 \%$, ou R\$ 180 bilhões por ano.

Para Lottenberg (2010), o aumento dos gastos com a saúde está diretamente ligado à evolução na tecnologia médica (a Figura 1 exemplifica essa evolução), ao aumento na expectativa de vida e aos métodos avançados de tratamento e diagnóstico de doenças. O aumento dos gastos, que giram em torno de $15 \%$ ao ano nos últimos 10 anos, não tem perspectiva de diminuição, isso porque o setor médico necessita de soluções diferenciadas.

\begin{tabular}{|c|c|c|}
\hline $\begin{array}{l}\text { Tecnologia } \\
\text { Tradicional }\end{array}$ & $\begin{array}{c}\text { Tecnologia } \\
\text { Atual }\end{array}$ & $\begin{array}{c}\text { Novas } \\
\text { Tecnologias }\end{array}$ \\
\hline $\begin{array}{c}\text { Equipamento de Raios } \\
X \\
\$ 175,000\end{array}$ & $\begin{array}{c}\quad \begin{array}{l}\text { Tomografia } \\
\text { Computadorizada - CT } \\
\$ 1.000,000\end{array} \\
-\end{array}$ & $\begin{array}{c}\text { PET/CT } \\
\$ 2,300,000\end{array}$ \\
\hline $\begin{array}{c}\text { Instrumental para } \\
\text { cirurgia aberta } \\
\$ 10,000\end{array}$ & $\begin{array}{c}\text { Instrumental para } \\
\text { cirurgia Laparoscópica } \\
\$ 15,000\end{array}$ & $\begin{array}{c}\text { Equipamento para cirurgia } \\
\text { Robótica } \\
\$ 2,000,000\end{array}$ \\
\hline $\begin{array}{l}\text { Balăo Cardiaco } \\
\$ \$ 500\end{array}$ & $\begin{array}{c}\text { Stent } \\
\$ 2,300\end{array}$ & $\begin{array}{c}\text { Fármaco - Stent } \\
\$ 6,000\end{array}$ \\
\hline $\begin{array}{l}\text { Bisturi } \\
\$ 20\end{array}$ & $\begin{array}{l}\text { Equipamento } \\
\text { Eletrocirürgico } \\
\$ 12,000\end{array}$ & $\begin{array}{l}\text { Bisturi Harmônico } \\
\$ 30,000\end{array}$ \\
\hline
\end{tabular}

Figura 1: Novas tecnologias na saúde. Fonte: Lottenberg (2010)

$\mathrm{O}$ aumento na expectativa de vida, citado anteriormente, resulta no aumento 
da demanda por serviços de saúde. Esse fator tem uma extrema importância nos custos de saúde per capita pois, com uma maior população com idade superior a 65 anos, os custos tendem a ser de três a cinco vezes maiores para esta faixa etária do que para qualquer outra grupo etário. $\mathrm{O}$ envelhecimento na pirâmide etária brasileira pode ser melhor observado na Figura 2.

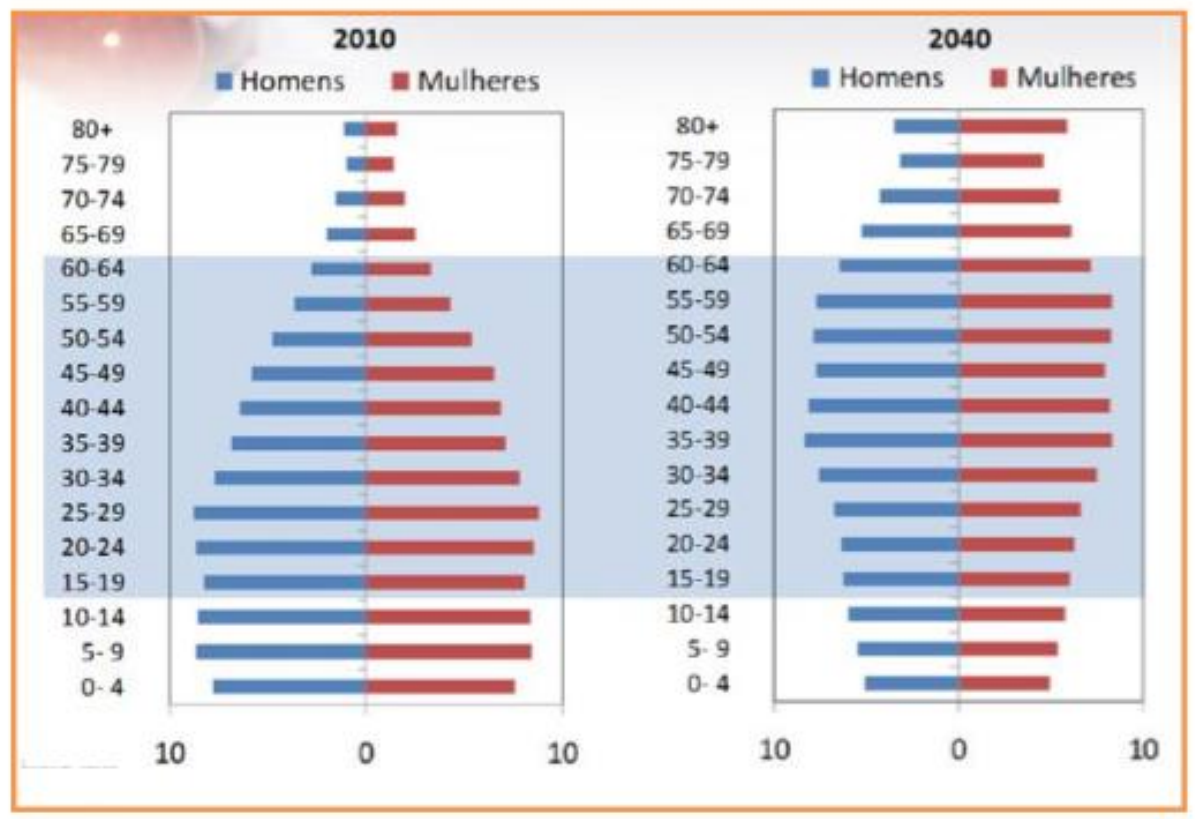

Figura 2: Pirâmide etária brasileira. Fonte: IBGE (2010)

Outro fator que gera o aumento nos custos dos hospitais é o estilo de vida da população do país. Anos atrás, as pessoas eram suscetíveis a doenças consideradas tradicionais, tais como a falta de saneamento e desnutrição, entretanto o crescimento da economia, a melhora na infraestrutura do país e o aumento no poder aquisitivo da população fizeram com que esses riscos tradicionais fossem substituídos por riscos modernos, tais como hipertensão e diabetes. Essas doenças crônicas possuem um tratamento mais complicado e consequentemente mais caro, já que um risco pode ser fator de risco para outros, como por exemplo, a obesidade é um fator de risco para a diabetes, problemas cardíacos, entre outros.

Desse modo, os gastos com a saúde tendem a aumentar, especialmente no Brasil onde os níveis históricos mostram que os gastos são menores que os de países desenvolvidos.

Para Falk (2001), esse aumento nos gastos com o setor da saúde gerou uma ampliação nos serviços hospitalares e consequentemente uma maior demanda por 
pessoas qualificadas e pela aplicação de métodos de gestão mais profissionais, que busquem atender a exigência dos clientes.

A constante busca por melhorias que diminuam ou até eliminem os desperdícios na saúde juntamente com o crescente aumento nos gastos, faz com que o desafio de melhorar os resultados das organizações de saúde se tornem evidente. No setor privado a busca é sempre pelo alto nível do serviço prestado, utilização de tecnologia diferenciada, otimização operacional e o marketing e segmentação. Entretanto, no setor público os responsáveis pela gestão estão mais focados na expansão e na modernização dos hospitais, na busca pela eficiência, na redução dos custos dos serviços não assistenciais e também na melhoria dos processos de atendimento.

Para Porter e Teisberg (2007), criar valor para o paciente é a melhor maneira de se ter um complexo industrial da saúde eficiente e competitivo, pois são os pacientes quem irão desfrutar das reduções de custo. Porter e Teisberg (2007) afirmam também que o foco principal desta solução tem que ser direcionado aos prestadores de serviços de saúde (clínicas, hospitais, unidades de atendimento e grupos de médicos), já que essas unidades de saúde são as responsáveis por agregar maior valor em qualidade de saúde ao cliente final.

\subsection{Caracterização dos Hospitais}

Os hospitais são geralmente divididos em três tipos de categorias:

- Hospital Filantrópico - Mantido parcialmente ou integralmente por meio de doações, membros de seus órgãos de direção e consultivos não sejam remunerados, que se proponha à prestação de serviços gratuitos à população carente em seus ambulatórios, reservando leitos, de acordo com a legislação em vigor, ao internamento gratuito, organizado e mantido pela comunidade e cujos resultados financeiros revertam exclusivamente ao custeio de despesa de administração e manutenção (SNABS, 1977).

- Hospital Público - Para Paes (2009), é um hospital controlado pelo governo estadual, local ou federal, assistindo a população em geral. Grande porcentagem de leitos é destinado ao SUS (Sistema Único de Saúde), que paga uma taxa diária fixa para cada tipo de atendimento. 
- Hospital Particular - É o hospital que integra o patrimônio de uma pessoa natural ou jurídica de direito privado (com fins lucrativos) não instituída pelo Poder Público. Atende principalmente a convênios (planos de saúde) e pacientes particulares.

Além da divisão por categorias, os hospitais também podem ser classificados por sua quantidade de leitos. Nessa classificação os hospitais podem ser definidos como de porte pequeno, médio, grande e extra grande. Essa classificação é melhor explicada pela Tabela 1.

Tabela 1 Classificação dos hospitais gerais por porte. Fonte: SIPNASS (2006)

\begin{tabular}{cc}
\hline Porte & \# de Leitos \\
\hline Pequeno & Até 50 \\
Médio & 51 a 150 \\
Grande & 151 a 500 \\
\hline Extra Grande & Acima de 500 \\
\hline
\end{tabular}

Assim como em todo o mundo, no Brasil a consciência de que se deve gerar valor ao cliente através da melhoria nos processos, na qualidade do serviço e otimizar recursos ainda é incipiente porém já começa a ter adeptos em diversas unidades de saúde. Ainda que atrasado em relação a países mais desenvolvidos no setor, no Brasil, já se pode notar maior preocupação dos stakeholders, especialmente no que afeta planos de saúde, hospitais públicos e privados.

\subsection{Taxonomia}

Uma das maneiras de se entender as operações que ocorrem dentro de um hospital é entendendo primeiramente todo o funcionamento de um hospital e a sua taxonomia (ciência da classificação). Esse entendimento é de suma importância visto que as unidades hospitalares têm estrutura e funcionamento complexos, com unidades que se inter-relacionam, estando ou não envolvidas diretamente no processo de atendimento de um paciente. Cada uma das unidades tem 
características e necessidades específicas, precisando de atenções diferenciadas.

De acordo com Hans et al (2012 b), o planejamento e controle das decisões são tomadas pelas organizações de saúde para montar e operar os processos de gestão de saúde. Além disso, é apresentado um esquema de divisão hierárquica em três áreas, bem como uma divisão em áreas gerenciais em quatro áreas. As três áreas hierárquicas em que são divididas as organizações de saúde são estratégica, tática e operacional. Esta última apresenta uma subdivisão em online e offline. Já as áreas administrativas são divididas em planejamento médico, planejamento financeiro, planejamento de materiais e planejamento e capacidade dos recursos (Hans et al 2012 A e Hans et al 2012 B).

A divisão hierárquica pode ser definida da seguinte forma:

- Estratégica: Nível mais elevado da hierarquia, compreende presidentes, diretores e demais gestores da alta cúpula e decidem os objetivos globais da empresa. Avaliam as tendências do mercado, a situação financeira do mesmo e a sua influência na organização, analisam as mudanças de comportamento do consumidor e qual serão as estratégias políticas e financeiras para adaptar-se às adversidades encontradas.

- Tático: Nesse nível estão inclusos os chefes de cada seção e os gerentes. Nessa posição as tarefas a serem desempenhadas são da área organizacional (financeiro, recursos humanos, linhas diferenciadas de produtos e etc). Esse nível administrativo é também responsável pela implementação das decisões estratégicas tomadas pelo nível acima.

- Operacional: Nesse nível os administradores devem extrair o máximo das potencialidades do colaborador através das ferramentas administrativas que lhe são concedidas, seu papel é aperfeiçoar a produção de bens e serviços de maneiras satisfatórias em curto prazo, sempre seguindo as diretrizes estabelecidas no nível tático. Dentre os cargos inerentes a essa posição podemos citar os chefes de equipe e supervisores.

A subdivisão do nível operacional para o caso da gestão de saúde é definida por Hans et al (2012 B) da seguinte forma:

- Online: Tomada de decisão em tempo real a respeito de eventos que não podem ser planejados com antecedência.

- Offline: Tomada de decisão previamente planejada 
De acordo com Hans et al (2012 b), cada uma das áreas administrativas pode ser definida da seguinte forma:

- Planejamento médico: Aborda a tomada de decisões pelas equipes clínicas sobre protocolos médicos, tratamentos, diagnósticos e triagem.

- Planejamento financeiro: Aborda como uma organização deve gerenciar seus custos e receitas para alcançar seus objetivos em circunstâncias organizacionais e econômicas atuais e futuras.

- Planejamento de materiais: Aborda a aquisição, armazenamento, distribuição e recuperação de todos os recursos / materiais de consumo, tais como materiais de sutura, sangue, ataduras, alimentos, etc.

- Planejamento e capacidade dos recursos: Aborda o dimensionamento, planejamento, agendamento, monitoramento e controle dos recursos renováveis

As divisões dos níveis hierárquicos e administrativos são melhores exemplificados na Figura 3.
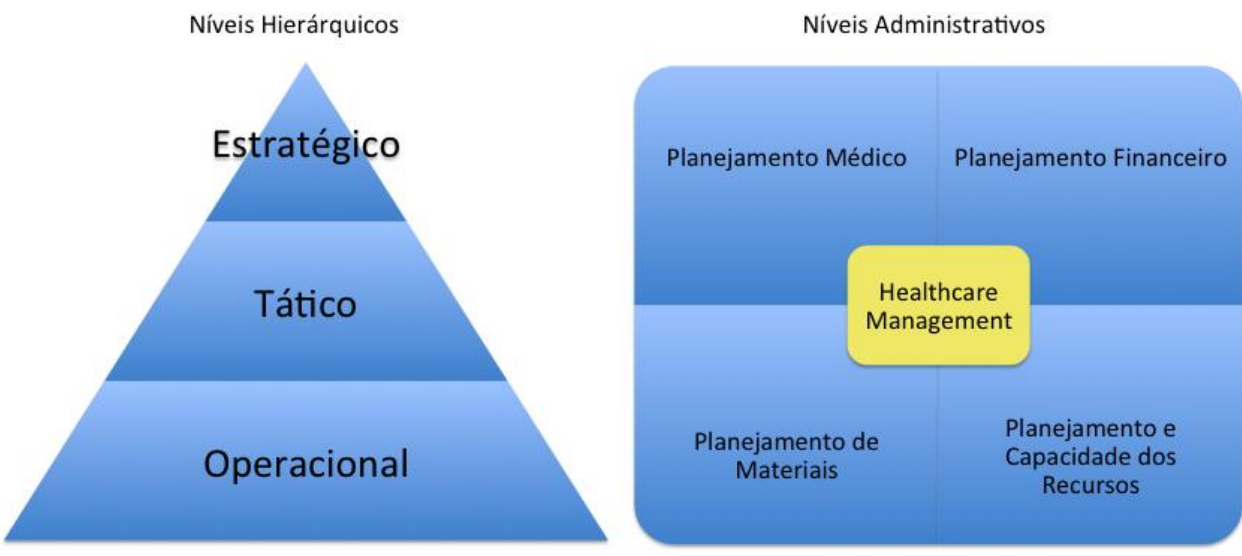

Figura 3: Níveis hierárquicos e administrativos. Fonte: Desenvolvido pelo autor

Hans et al (2012 b) definem que existem dois tipos de eixos para a taxonomia do planejamento e capacidade de recursos. Esses eixos formariam uma matriz com quadrantes explicitando onde estaria cada uma das decisões a serem tomadas.

No eixo vertical são representados a hierarquia de decisão de cada um dos níveis do hospital. No eixo horizontal são representados cada um dos diferentes serviços de um hospital. Na Figura 4 pode-se entender melhor como estão dispostos o serviços e os níveis hierárquicos da gestão de saúde. 


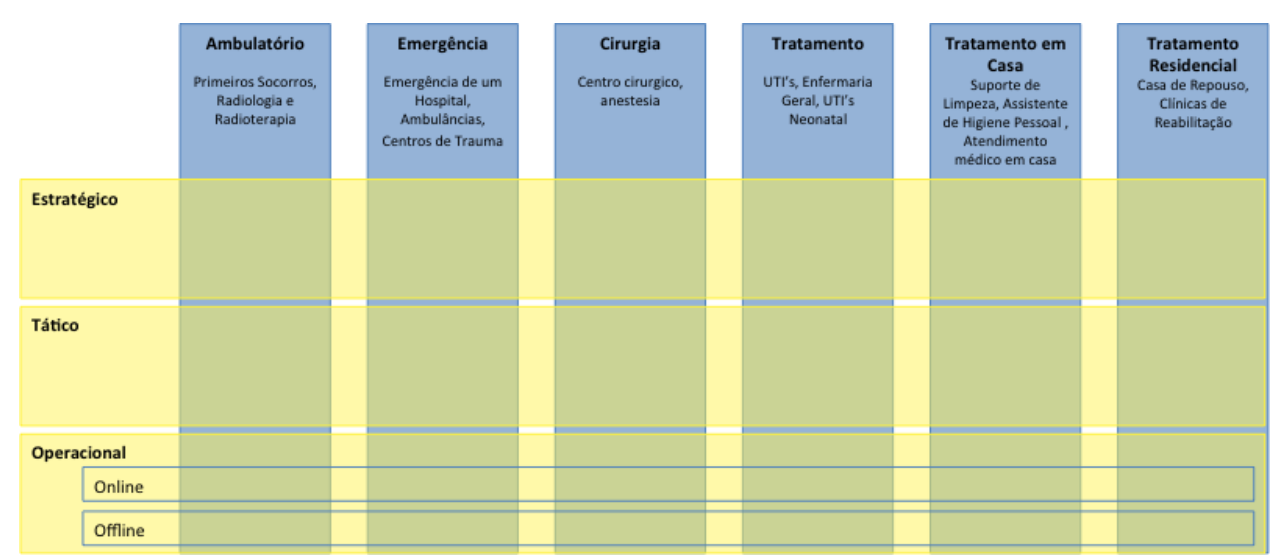

Figura 4: Serviços e níveis hierárquicos. Fonte Hans et al (2012 b)

Porter e Teisberg (2006) definem que, no nível estratégico, as questões da assistência a saúde podem ser divididas em três amplas áreas:

- Custo e acesso ao seguro saúde;

- Normas de cobertura ou tipos de tratamento que devem ser cobertos pelo seguro versus o que deveria ser responsabilidade do indivíduo;

- Estrutura da prestação dos serviços de saúde.

Além disso, Porter e Teisberg (2006) creem que a estrutura da prestação dos serviços de saúde é a questão mais fundamental, embora a maior parte da atenção recaia sobre o seguro.

Porter \& Teisberg (2006) classificam os prestadores de serviços como uma organização de “estrutura funcional". Essa instituição é composta por departamentos que representam as especialidades médicas, onde alguns recursos são de uso comum (centro cirúrgicos, ambulatórios, UTI's etc.). Além disso, cada uma dessas unidades pode apresentar "subunidades", onde os pacientes recebem atendimento.

É importante ter uma visão geral da organização hospitalar para o estudo de sua cadeia de suprimentos. Isto porque cada uma dessas unidades possui estoques menores, que são abastecidos pelo setor de suprimentos central. Em cada posto de enfermagem existe uma pequena área para armazenamento de materiais e medicamentos que possam ser utilizados sem que seja necessário solicitar ao dispensário central, agilizando o atendimento.

Slack et al. (2008) classificam os processos como transformadores de entradas em saída. No que diz respeito aos processos hospitalares, podemos dividi-los em três grandes sub-grupos: 
- Clínicos, relacionados diretamente à prestação de serviço de saúde ao paciente.

- Administrativos, de apoio à gestão da organização hospitalar, representados por faturamento, admissão do paciente e outros.

- De suporte, onde estão os que apoiam a prestação de serviço médicohospitalar, como suprimentos, limpeza, lavanderia e cozinha.

Desse modo, esta dissertação, de acordo com Hans et al. (2012 b), irá focar mais nos níveis hierárquicos tático e operacional com o objetivo de melhorar o planejamento e operação dos processos escolhidos. De acordo com Slack et al. (2008) o objetivo desta dissertação é focar nos processos que estão diretamente ligados à prestação de serviço ao paciente.

\subsection{Logística Interna de Medicamentos}

Aptel e Pourjalali (2001), Ramani (2006) e Naidu (2009), afirmam que nos hospitais, as variabilidades de demanda e tempo de atendimento são comuns, desse modo a logística exerce uma função relevante ao agregar valor para a organização e seus clientes, vez que a falta de um item de estoque pode ocasionar problemas na qualidade do serviço prestado ao paciente, assim como a aquisição de urgência, acarretará custos não previstos para o hospital.

Para Vecina Neto e Reinhardt Filho (1998) uma das maiores dificuldades da logística de medicamentos é a cadeia de processos que estes percorrem dentro da instituição, da sua compra até a sua utilização por um paciente (Figura 5).

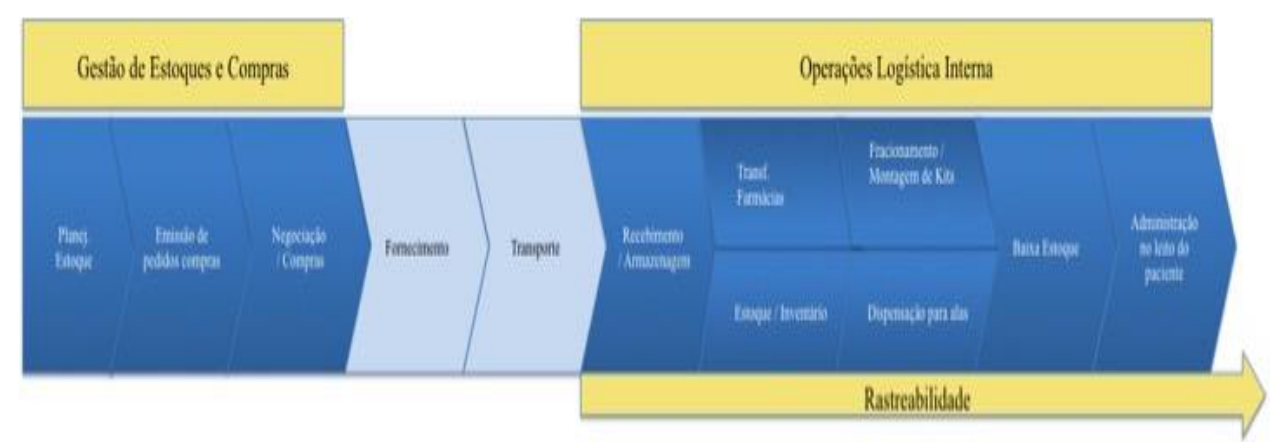

Figura 5: Processos do fluxo de medicamentos. Fonte: Desenvolvido pelo autor

Esses processos precisam estar interligados para que a logística funcione de maneira adequada. Caso isso não aconteça podem gerar um alto impacto no custo 
de um hospital. Entretanto boa parte desse custo é devido as perdas, mau uso ou desperdício (Azevedo Neto, 2010).

Além da problemática dessa cadeia de processos, os medicamentos desde sua entrada passam por diversos elos na cadeia hospitalar interna antes de chegar ao leito, onde são administrados aos pacientes pelos enfermeiros. Essa complexidade do fluxo dos medicamentos dentro do hospital está melhor exemplificada na Figura 6.

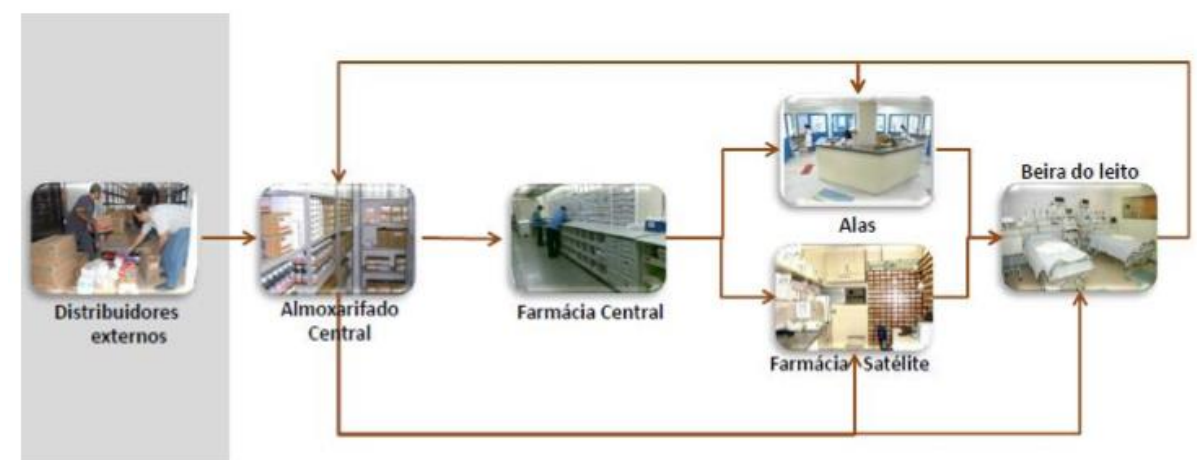

Figura 6: Exemplo de fluxo de medicamentos e materiais hospitalares dentro de hospitais. Fonte: Desenvolvido pelo autor

Para Jacobi (1994), o setor hospitalar requer um trabalho de pesquisa de novas metodologias e técnicas com o objetivo de minimizar as complexidades do setor que não são existentes em outras áreas industriais.

Dentre as nuances do setor, os medicamentos são os que possuem a maior complexidade. Isso acontece devido a várias peculiaridades, conforme podemos observar na Figura 7, que outros insumos não possuem como:

- Prazo de validade exíguo;

- Obrigatoriedade da rastreabilidade;

- Controle separado de cada lote;

- Necessidade de conversão de unidades (caixa, cartela, unidades);

- Obrigatoriedade de ser homologado pela ANVISA - Agência Nacional de Vigilância Sanitária. 


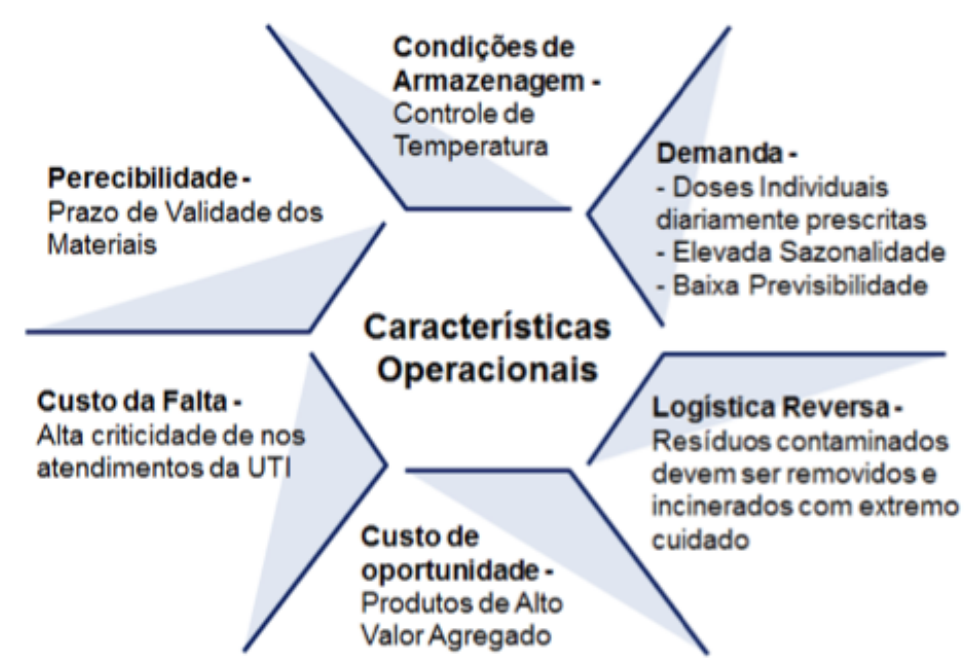

Figura 7: Alta complexidade das características operacionais dos insumos médicohospitalares. Fonte: Desenvolvido pelo autor

Segundo Klügl et al. (1999), os medicamentos estão entre os principais componentes dos custos de um hospital, logo um emprego racional dos produtos pode levar a uma redução de custos. Além disso, Vecina Neto e Reinhardt Filho (1998) afirmam que as despesas com materiais e medicamentos chegam a representar de 15 a $25 \%$ dos custos de um hospital.

Sendo assim, o planejamento hospitalar deve focar na otimização dos processos que compõem a logística de suprimentos (medicamentos, material médico-hospitalar, produtos saneantes, alimentos, material de escritório, etc.) buscando uma maior eficiência e soluções para os problemas que venham eventualmente a aparecer.

\subsubsection{Unitarização de Medicamentos}

O fracionamento de medicamentos é uma atividade que faz com que os remédios possam ser enviados aos pacientes nas quantidades que estão previstas pela prescrição médica. Desse modo o medicamento é dividido em partes individuais para atender ao tratamento recomendado pelo médico. A embalagem que é fracionada é chamada de embalagem primária fracionável, Figura 8, e deve ser aprovada pela ANVISA para ser feita com esse objetivo (ANVISA, 2006). 


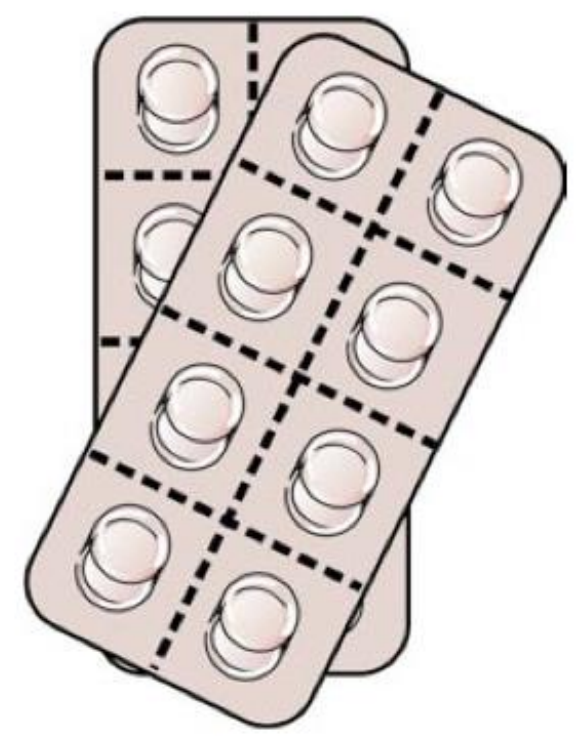

Figura 8: Embalagem primária fracionável. Fonte: Guia para Farmacêuticos de Medicamentos Fracionados, ANVISA (2006)

Segundo a ANVISA (2006), o fracionamento deve ser acompanhado e supervisionado por um farmacêutico e deve seguir alguns passos para ser realizado:

- Avaliação da prescrição pelo farmacêutico;

- Subdivisão da embalagem do medicamento em frações menores;

- Acondicionamento das unidades fracionadas nas novas embalagens;

- Retorno das embalagens restantes à embalagem original (Quando restarem embalagens);

- Rotulagem da embalagem unitarizada (com nova validade e informações exigidas pela $\mathrm{RDC} \mathrm{n}^{\circ}$ 80/2006);

- Registro das operações relacionadas à dispensação;

- Restituição da receita ao usuário, devidamente carimbada em cada item dispensado e assinada pelo farmacêutico;

- Envio do medicamento unitarizado ao paciente.

De acordo com a ANVISA (2006), a dispensação e o fracionamento dos medicamentos devem ocorrer no mesmo lugar.

Além da supervisão, o medicamento fracionado deve estar em uma embalagem especial aprovada pela ANVISA, também conhecida como embalagem secundária fracionada, e que deve conter as seguintes informações (ANVISA, 2006): 
- Razão social e endereço da farmácia onde foram realizados o fracionamento e a dispensação;

- Nome e inscrição no CRF (Conselho Regional de Farmácia) do farmacêutico responsável pela unitarização;

- $\quad$ Nome comercial do medicamento, quando este não for genérico;

- Denominação Comum Brasileira (DCB) ou então Denominação Comum Internacional (DCI), caso sejam medicamentos fitoterápicos;

- Concentração, posologia e via de administração;

- Número do lote, data de fabricação e validade (mês/ano);

- Advertências complementares presentes na embalagem original;

- $\quad$ Nome da empresa titular do registro e número de telefone do SAC;

- Quando for um medicamento genérico, a embalagem deve conter "Medicamento Genérico;

- Lei n 9.787, de 1999”.

Além disso segundo a ANVISA (2006), é de extrema importância que o medicamento unitarizado contenha uma bula do respectivo medicamento.

Os medicamentos que podem ser fracionados são os que possuem as seguintes formas: comprimidos, cápsulas, óvulos vaginais, drágeas, adesivos, transdérmicos e supositórios. Além desses, os medicamentos que se apresentam como frasco-ampola, ampola, seringa, flaconete, sachê envelope, blister, entre outros, também podem ser fracionados (ANVISA, 2006).

Para os medicamentos líquidos orais há uma certa diferença, pois não basta somente cortar a embalagem primária fracionável. No caso desse tipo de medicamento, a ASHP (1985), American Society of Hospital Pharmacists, definiu as seguintes normas listadas abaixo:

- Os recipientes devem ser preenchidos com o conteúdo rotulado. Pode ser necessário que o recipiente seja enchido um pouco mais do que a dosagem dependendo da forma ou do material do recipiente e a formulação da forma da dosagem;

- A etiqueta deve conter as quantidades enviadas em mg (ou g ou mcg) e ml;

- As seringas de uso oral não podem ser utilizadas com agulhas e na etiqueta deve conter "Somente para uso oral"; 
- Os recipientes devem ser projetados para permitir a administração de conteúdos diretamente do recipiente.

\subsubsection{Dispensação}

A dispensação é uma atividade de extrema importância na logística hospitalar e com grande impacto na farmácia hospitalar, de acordo com o guia básico para farmácia hospitalar, Ministério da Saúde do Brasil (1994).

A distribuição de medicamentos pode ser realizada de três formas distintas: Distribuição Coletiva, Distribuição Individualizada e Dose Unitária.

Para Finotti (2010), o sistema de dispensação coletivo é o sistema mais antigo que existe, porém ainda é muito utilizado por hospitais brasileiros. Esse sistema tem como principal característica a distribuição de medicamentos por unidade de internação a partir de um pedido da enfermagem. Além disso, os remédios são enviados em suas embalagens originais não importando quantas doses serão ministradas ou por quanto tempo o médico receitou o medicamento (Freitas, 2004).

Ainda de acordo com Finotti (2010), as principais vantagens desse sistema de distribuição são a disponibilização imediata, redução das prescrições médicas e redução do quadro de funcionários da farmácia. Entretanto, há desvantagens também como duplicação de doses, administração de medicamentos não prescritos, perdas e furtos.

No sistema de distribuição individualizado o medicamento é enviado por paciente para um período de 24 horas, podendo ser dividido em envio direto e indireto (Finotti, 2010).

No sistema direto, não há uma transcrição da prescrição médica com uma participação direta do farmacêutico. Além disso, os medicamentos podem ser dispostos em embalagens originais ou fracionados, nesse caso em sua maioria são comprimidos devido à facilidade de unitarização (Freitas, 2005). No sistema indireto há uma transcrição da prescrição médica que é utilizada pela farmácia, enviando os medicamentos para o paciente e não para a unidade (Finotti, 2010).

Dentre as vantagens do sistema individualizado estão o maior controle sobre o estoque dos medicamentos, a possibilidade de revisão das prescrições e a redução dos estoques. As desvantagens do sistema individualizado são os erros nas distribuições, perda de tempo com o fracionamento e a necessidade de 
investimentos. Freitas (2005) afirma ainda que no sistema indireto problemas nas transições das prescrições podem gerar mais erros.

O sistema de dispensação unitária ou Sistema de Distribuição de Medicamentos por Dose Unitária, SDMDU, de acordo com Finotti (2010) é o sistema onde todas as formas farmacêuticas estão prontas para o uso. Nesse sistema a solicitação da medicação é feita a partir de uma cópia da prescrição médica, física ou digitalizada (via algum sistema), para o paciente e por 24 horas. A medicação é sempre preparada por dose e concentração de acordo com a prescrição e ministrada nas embalagens unitarizadas.

Nesse sistema as principais vantagens são redução dos erros de medicação, perdas, furtos, redução dos estoques e diminuição nas devoluções. A principal desvantagem é o seu custo de implementação, segundo Ribeiro (1993).

Segundo Napal et al (2002), a principal vantagem do sistema SDMDU, em relação aos outros métodos de dispensação, é a segurança para o usuário de medicamentos em relação aos erros de medicação.

Logo, tendo compreendido como funciona os processos e as atividades que ocorrem dentro de um hospital, pode-se dizer agora com um melhor embasamento de que este trabalho focara na logística hospitalar de medicamentos e mais especificamente no processo de unitarização e dispensação dos medicamentos.

\subsection{Gestão do Estoque}

Neste subcapítulo serão abordadas literatura sobre centralização de estoque e política de estoque. Isso se deve ao fato desses conceitos estarem presentes quando se faz análises dos processos de unitarização e dispensação além de serem importantes também para tomadas de decisão.

Ao se gerir medicamentos na área hospitalar depara-se com um universo com diversas opções, pois existem aproximadamente cinco mil itens disponível no mercado (Portella, 2001).

Assim, a escolha do local e das funções das instalações de armazenagem é considerada uma decisão estratégica (Rodrigues e Pizzolato, 2003). Para Lacerda (2000), a decisão do posicionamento da armazenagem é parte de um conjunto integrado de decisões nas quais são envolvidas algumas políticas, tais como 
serviço ao cliente, estoque, transporte, produção, com o objetivo de prover um fluxo de materiais e produtos eficiente ao longo de toda a cadeia.

Barbieri e Machline (2006) afirmam que o valor monetário dos estoques na saúde não é o único fator para o dimensionamento, mas também tem que ser levada em conta o qual essencial é o medicamento para a prestação de serviços a que dão suporte. Portella (2001) completa essa informação analisando que nesses estoques não pode haver excessos, implicando em alto custo, nem a falta de medicamentos, podendo levar ao óbito de pacientes.

Rodrigues e Pizzolato (2003), entretanto afirmam que essa definição mais tradicional tem passado por transformações, pois envolvem serviços mais complexos que a estocagem a curto e médio prazo. Esses serviços visam agilizar gilizar o fluxo de materiais, comprimindo o tempo entre o recebimento e a entrega dos pedidos, para reduzir os investimentos em estoque. Desse modo, o principal objetivo da armazenagem tem sido prover capacidade de resposta rápida reduzir as necessidades de estoque (Rodrigues e Pizzolato, 2003).

Em Giannoccaro e Pontrandolfo (2000), considera-se que a gestão de estoque trata dois tipos de decisão na cadeia de suprimentos: estratégicas e táticas. Nas questões estratégicas estão inclusas definições sobre estoques na cadeia, local onde deve estar situado e qual abordagem deve ser adotado para o seu controle.

Para Wanke (2000) alguns fatores devem ser analisados quando se determina a localização de um centro de distribuição e um maior ou menor grau de centralização. Dentre esses fatores pode-se citar características do produto, comportamento da demanda, nível de exigência do mercado, grau de flexibilidade do processo de fabricação, acesso à informação em tempo real e existência de economias de escala no transporte.

Em Calazans (2001) são apontadas algumas vantagens para a centralização do estoque. Entre elas pode-se destacar redução do custo de transporte, liberação de espaço nas lojas, redução de mão-de-obra nas lojas para o recebimento e conferência de mercadorias e a diminuição da falta de produtos nas lojas.

Bowersox \& Closs (2001) mapearam que ao se adotar um centro de distribuição em um sistema logístico é possível obter as seguintes vantagens, a capacidade de agregar valor ao produto (postergação) e os diferentes tipos de operações que podem ser realizadas no $C D$ - consolidação, break bulk, crossdocking e formação de estoque. 
O fornecedor em caso de adoção de um centro de distribuição obtém um ganho pois consegue atender o cliente com uma maior qualidade, visto que este acaba sendo servido mais rapidamente a partir de locais mais próximos. (Pizzolato \& Pinho, 2003).

Já em relação a política de estoque Wanke (2000) define em (1) quanto pedir, (2) quando pedir, (3) quanto manter em estoques de segurança, (4) onde localizar. Essa definição é completada com o acréscimo dos procedimentos e rotinas que devem ser adotados como apoio a estas decisões por exemplo: para definição da política de estoques, são avaliados os custos de: colocação de pedidos, falta de estoque, armazenagem, ineficiência de produção, giro de estoque e descontos de preço por quantidade pedida para decidir quanto comprar (Slack 2002). Porém, o gerenciamento de centenas de itens de estoque para controle é mais complexo devido a sua diversidade (Partovi e Anandarajan, 2002).

Para Hautaniemi e Pirttilä (1999), as políticas de reposição de estoque, tais como MRP, Pontos de Ressuprimento (PR) e sistemas de revisões visuais como "two-bin" são considerados mutuamente excludentes pela literatura de forma errônea.

Ballou (2001) afirma que se a demanda de um produto fosse determinística e a reposição fosse instantânea, não haveria a necessidade de um estoque de segurança, visto que esse só existe devido a incerteza da demanda e do lead time de fornecimento.

Buzzacott e Shanthikumar (1994), afirmam que uma alternativa para reduzir estas incertezas é o tempo de segurança que é aplicável quando se tem uma previsão bem acurada, variando apenas o lead time. Entretanto, flutuações da demanda durante o lead time diminuem sua atratividade por considerar a demanda constante.

Atualmente, é reconhecido pelas empresas que o desempenho dos sistemas de estoque não depende somente do planejamento realizado ou da forma como são controlados, mas também da arquitetura organizacional. Por isso, muitas, com o intuito de aprimorar, implementam ao mesmo tempo, avançados sistemas com o uso de medidas organizacionais (Vries, 2004). 


\section{Panorama da Saúde no Brasil}

Neste capítulo será apresentado um panorama da saúde no Brasil, com o objetivo de entender a quantidade de leitos, receitas e despesas além da quantidade de unidades de saúde presentes no país.

Nos últimos anos, o número de hospitais tem se mantido constante no Brasil apresentado uma queda desde 2011. Entretanto, quando analisamos os hospitais por tipo, vemos que os públicos têm apresentado um aumento na quantidade. Já os privados, com e sem fins lucrativos, tiveram uma queda de 2012 para 2013. Os dados podem ser traduzidos ao observarmos a Figura 9.

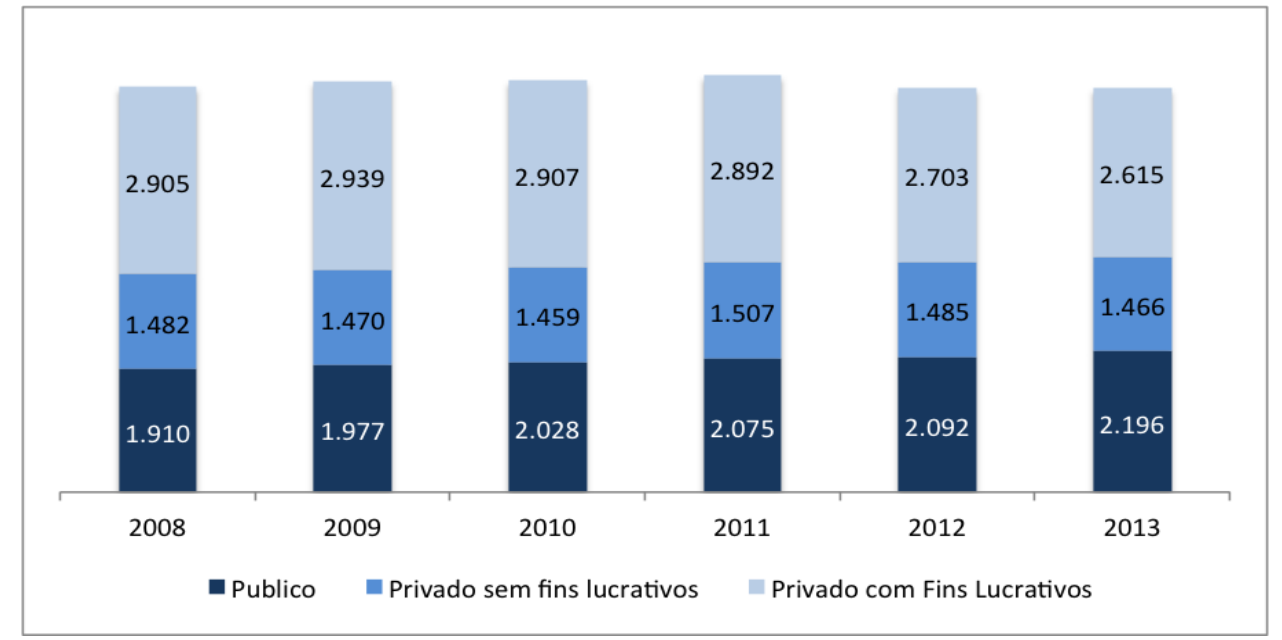

Figura 9: Quantidade de hospitais. Fonte: CNES/Ministério da Saúde, Painel ANAHP (2013)

O país possui aproximadamente 448 mil leitos nos 6.277 hospitais. Entretanto, os hospitais públicos possuem apenas $36 \%$, o restante são leitos dos hospitais privados, os quais incluem os hospitais com fins lucrativos e os sem fins lucrativos. Essa radiografia dos leitos é melhor explicitada na Figura 10. 


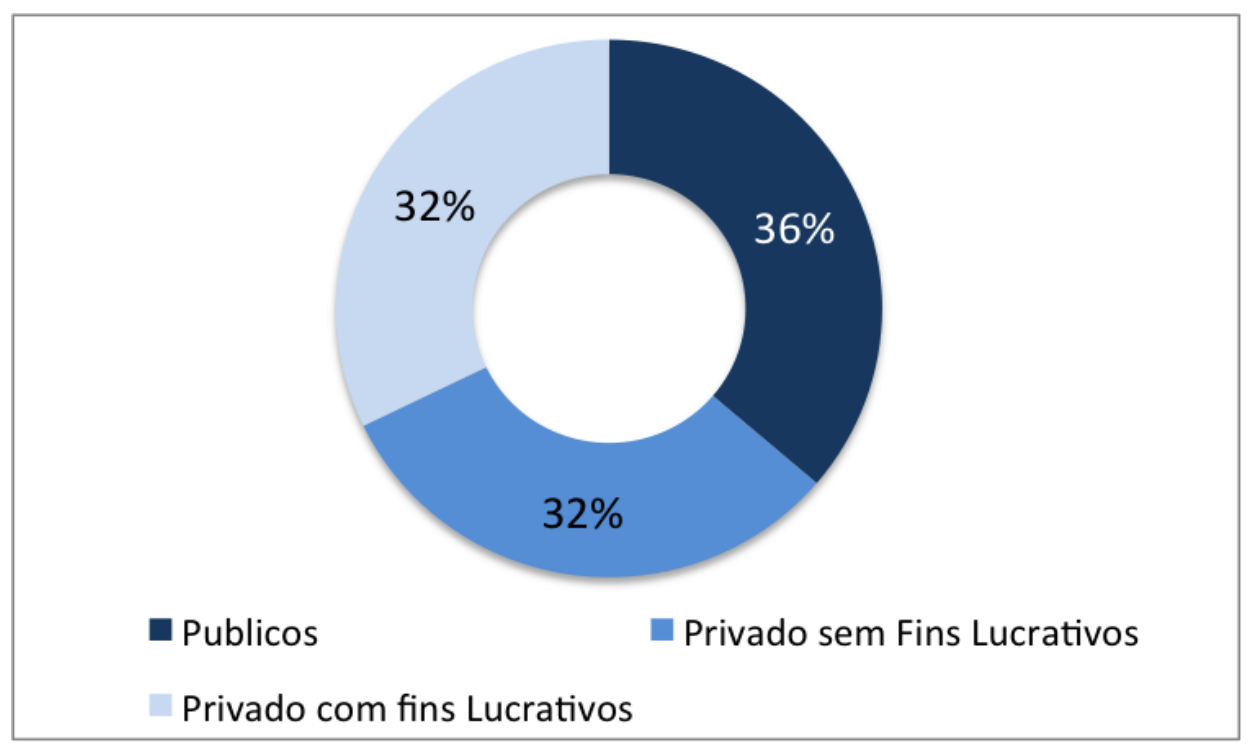

Figura 10: Radiografia dos leitos hospitalares. Fonte: CNES/Ministério da Saúde, Painel ANAHP (2013)

Dentre os leitos que observamos na Figura 10 entre hospitais públicos e privados (nesse incluímos os sem fins lucrativos e com fins lucrativos), há uma divisão entre os leitos SUS (Sistema Único de Saúde) e leitos não SUS em cada um dos tipos de hospitais avaliados. Essa divisão pode ser observada na Figura 11 e Figura 12.

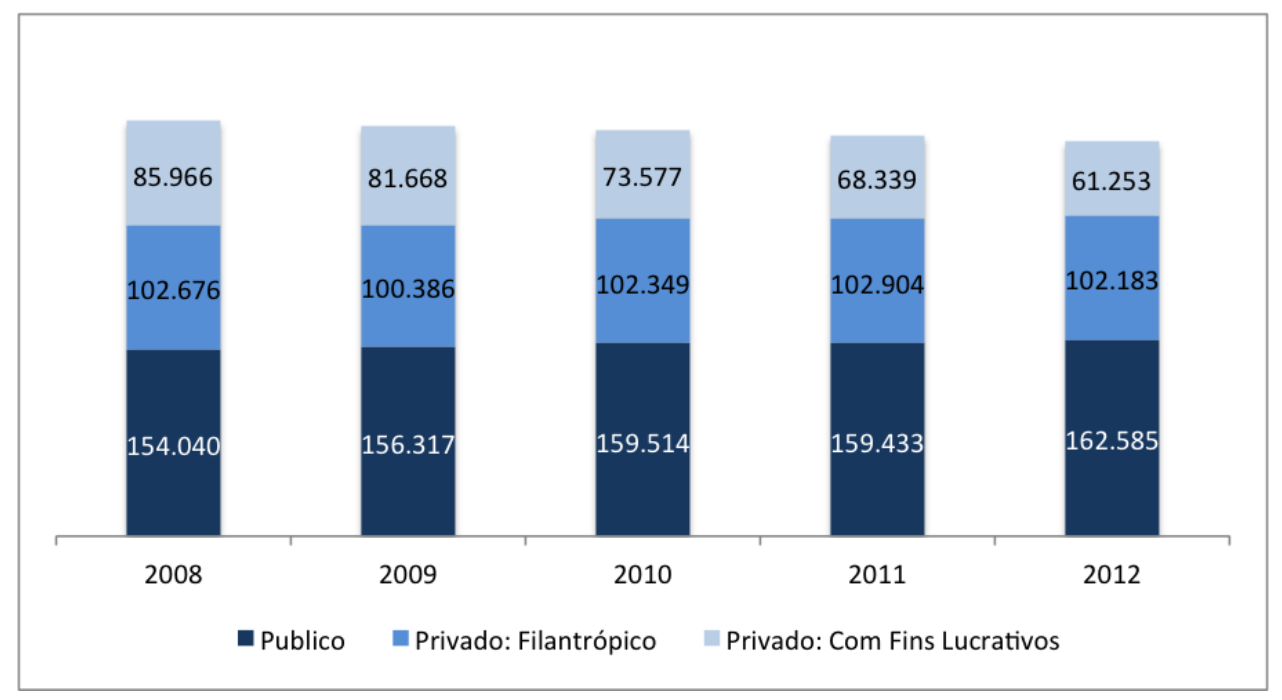

Figura 11: Quantidade de leitos SUS. Fonte: CNES/Ministério da Saúde, Painel ANAHP (2013) 


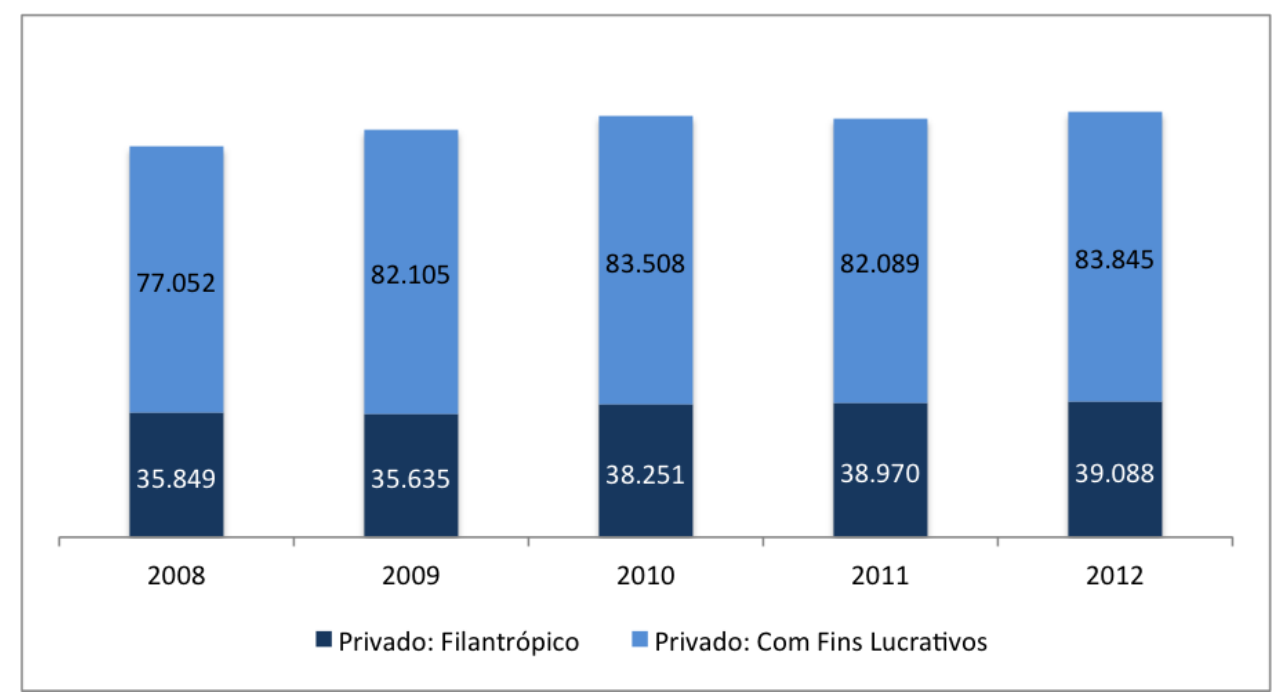

Figura 12: Quantidade de leitos não SUS. Fonte: CNES/Ministério da Saúde, Painel ANAHP (2013)

Além disso, o número de leitos por habitante no Brasil, de acordo com Estatísticas da Pesquisa Médico-Sanitária realizada pelo IBGE em 2009, vem diminuindo ao longo dos anos. Outro dado importante de se analisar também na Figura 13 é o fato do Ministério da Saúde orientar que a taxa de leitos por mil habitantes esteja numa faixa entre 2,5 e 3,0 leitos/mil habitantes e conforme observamos esse número está abaixo do recomendado.

Essa diminuição nos leitos vem acontecendo nos hospitais públicos devido a queda no desemprego e maior poder aquisitivo da população o que acabou criando uma demanda por planos de saúde. Assim, essa demanda migrou dos hospitais públicos para hospitais privados. Na Figura 13 pode-se observar a diminuição dos leitos SUS ao longo dos anos. 


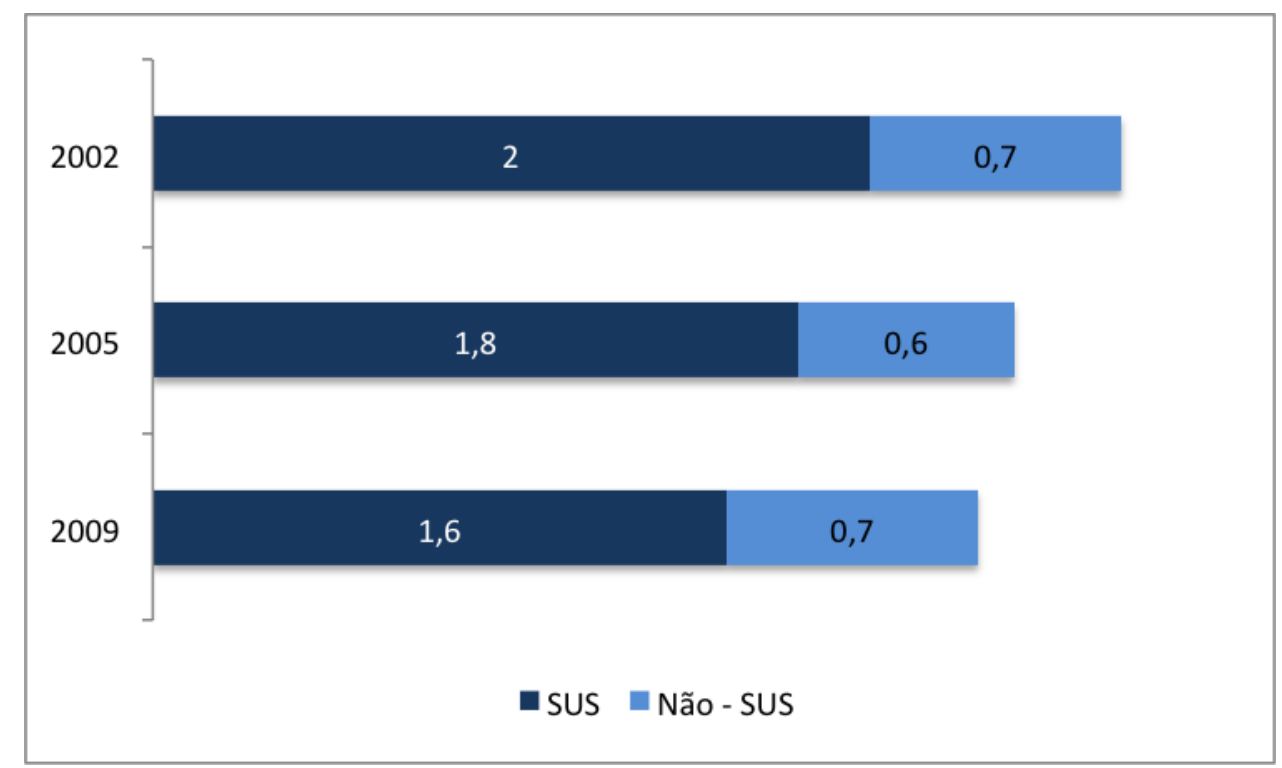

Figura 13: Leitos para internação por mil habitantes. Fonte: IBGE, Pesquisa MédicoSanitária 1999-2009

Apesar da queda do número de hospitais no Brasil, as receitas apresentaram um aumento de 12,4\%, conforme a Figura 14, de 2011 para 2012 passando de 82,4 bilhões de reais para 92,7 bilhões.

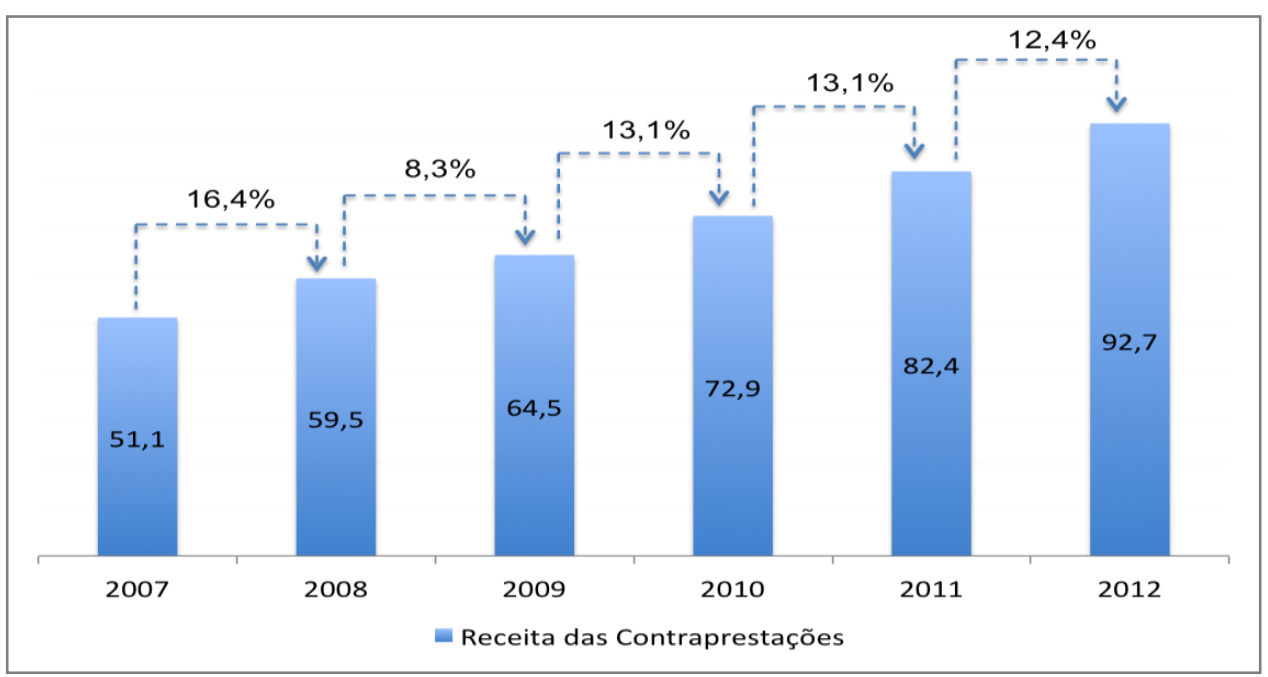

Figura 14: Receitas de contraprestações. Fonte: Observatório ANAHP 2013/ANS

Os hospitais vinculados à ANAHP, em linha com os outros hospitais do país, apresentaram no último ano um aumento no faturamento conforme a Figura 15. Observa-se que a receita média líquida se analisada por paciente por dia teve um crescimento de 5,7\% de 2011 para 2012, enquanto se analisarmos por saída hospitalar o crescimento foi de 6,0\%. É importante ressaltar também que o faturamento total dos hospitais ANAHP, em 2012, foi de 11,4 bilhões de reais. 


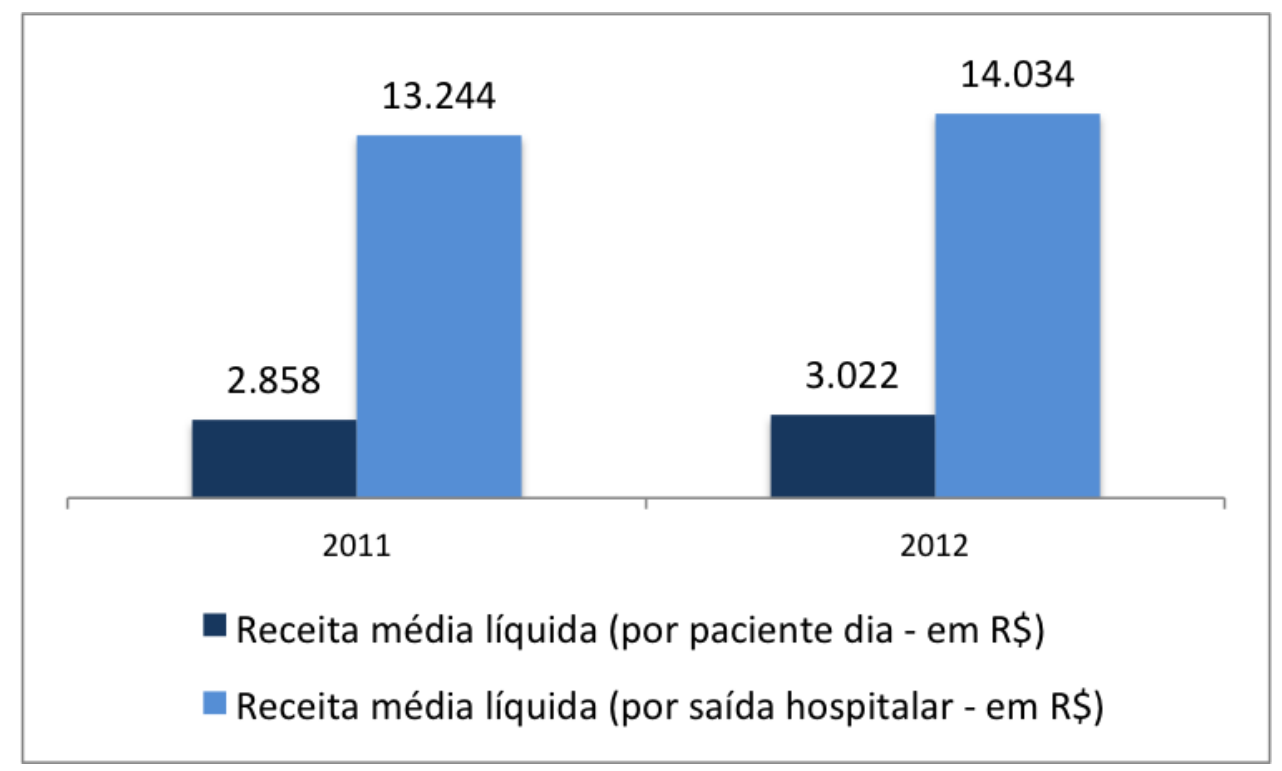

Figura 15: Faturamento hospitais ANAHP. Fonte: Sinha/ANAHP

Apesar de serem apenas uma parte dos hospitais privados do país, as unidades de saúde filiadas à ANAHP podem servir como uma amostra para se avaliar os hospitais privados em geral. Esse aumento nas receitas é explicado pelo aumento no número de clientes nos planos de saúde (Figura 16), isso porque com o maior número de pessoas utilizando planos de saúde a procurar pelo hospital particular aumenta, e o aumento na expectativa de vida da população que faz com que as pessoas necessitem de mais atendimento médico, acarretando em mais internações, mais exames (e em alguns casos mais caros) (Figura 17).

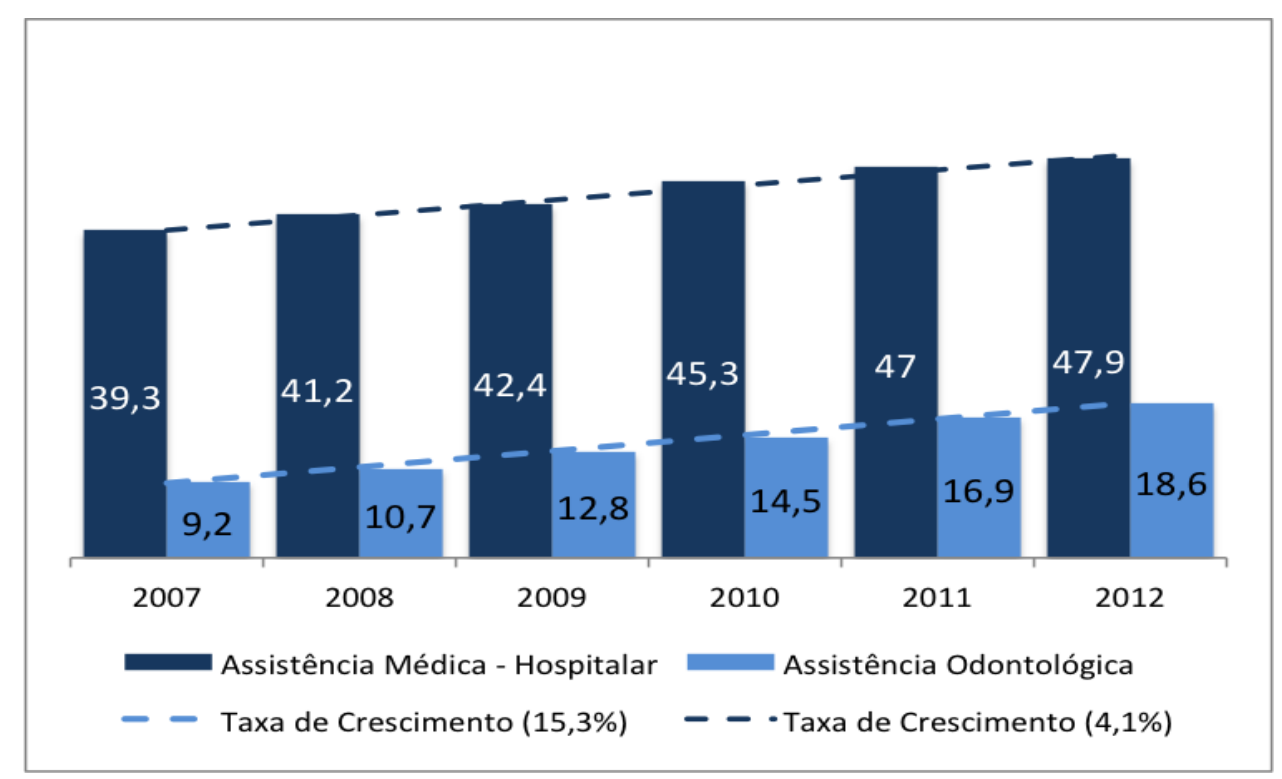

Figura 16: Número de beneficiários de planos de saúde. Fonte: Observatório ANAHP 2013/ANS 


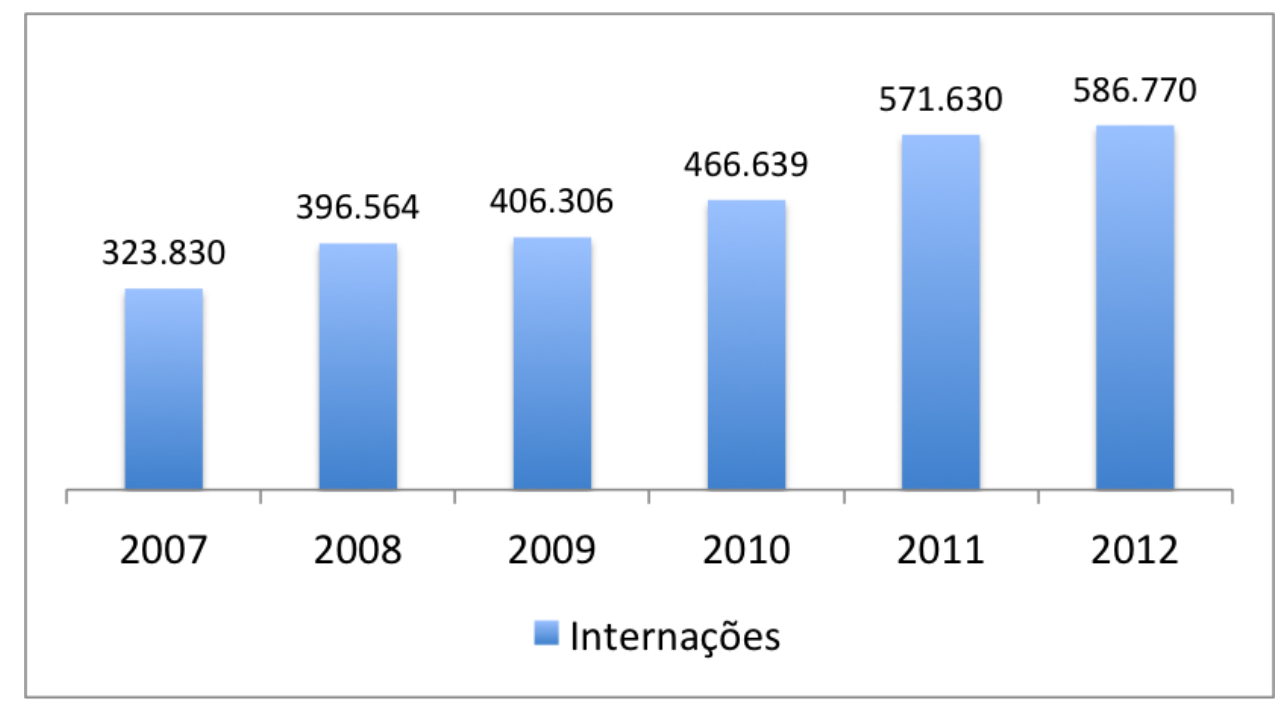

Figura 17: Total de internações. Fonte: Observatório ANAHP 2013/Sinha

Agora se observamos as receitas por tipo pode-se perceber que os insumos hospitalares são responsáveis por mais de $47,9 \%$ das receitas de um hospital (Figura 18). Porém apesar de representar quase 50\% das receitas, os insumos médico hospitalares apresentaram uma queda de 2011 para 2012, o que nos mostra que houve uma contenção de gastos por parte das operadoras. Entretanto, apesar da queda nos insumos, os valores do SADT (Serviços de Apoio à Diagnose e Terapia) apresentaram um leve aumento, não sendo suficiente para repor as perdas em materiais e medicamentos, pois não houve uma migração das receitas.

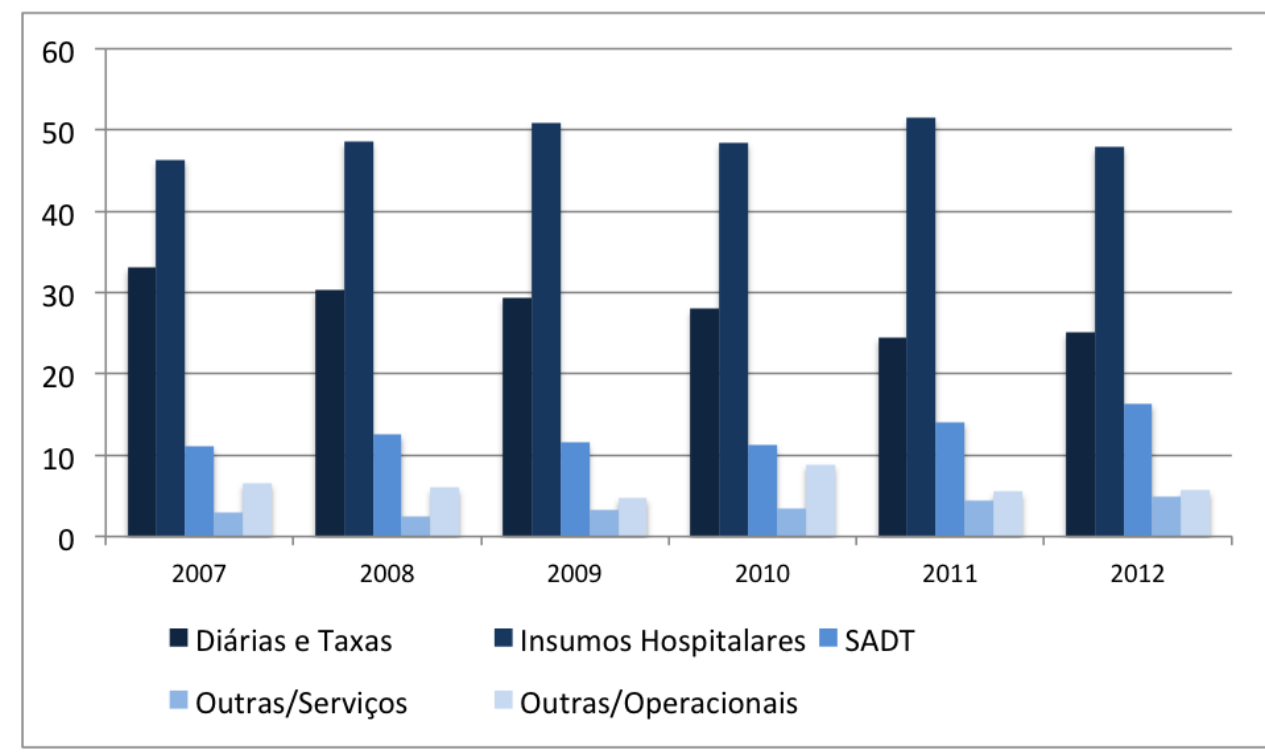

Figura 18: Distribuição da receita por tipo. Fonte: Observatório ANAHP 2013

Assim como as receitas dos hospitais da ANHAP que obtiveram um crescimento, as despesas assistenciais de 2012 cresceram 16\% (Figura 19) frente às despesas de 2011, sendo esse crescimento maior que o das receitas. Dentre as despesas, duas delas representam aproximadamente $70 \%$ do total das despesas, 
gastos com pessoal $(42,1 \%)$ e insumos hospitalares $(25,2 \%)$, conforme pode ser observado na Figura 20.

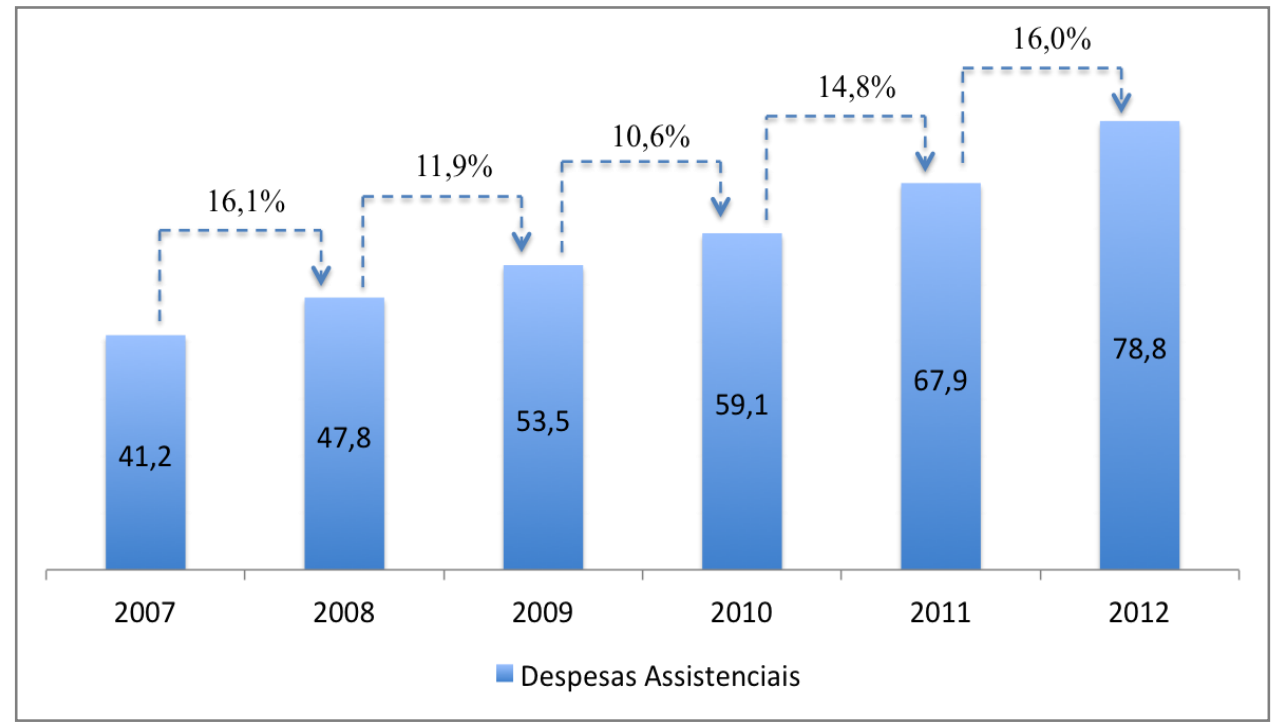

Figura 19: Despesas assistenciais. Fonte: Observatório ANAHP 2013/ANS

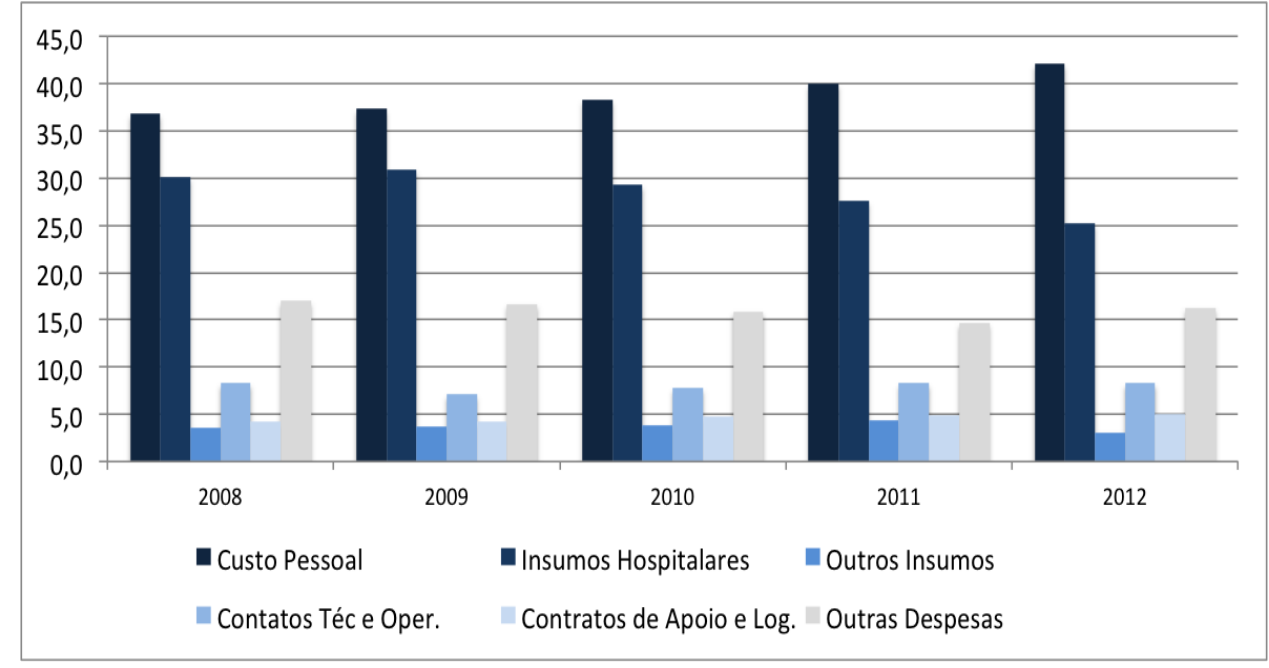

Figura 20: Distribuição das despesas nos hospitais ANAHP. Fonte: Observatório ANAHP 2013/Sinha

Desse modo, observando todos os dados apresentados anteriormente e analisando a quantidade de hospitais públicos e privados e seus respectivos leitos no país percebe-se que um hospital possui grandes oportunidades para estudos logísticos, principalmente se focar nos custos de pessoal e insumos hospitalares. Isso porque ambos estão diretamente conectados com todos os processos que ocorrem no hospital.

Assim, investimentos nos serviços prestados dentro do hospital podem resultar num crescimento das receitas com a redução de perdas com medicamentos, evitando também que os pacientes recebam a medicação trocada, 
criando uma vantagem competitiva no que diz respeito à qualidade da prestação do serviço. Além da vantagem competitiva na prestação do serviço, a realização de investimentos podem melhorar a dispensação, diminuindo o erro na administração de medicamentos aos pacientes e acarretando também em uma melhoria dos cuidados médicos. Outra vantagem de se investir nos serviços prestados é o melhor aproveitamento dos funcionários, que terão as suas tarefas otimizadas devido a otimização dos procedimentos realizados.

Assim nos próximos capítulos iremos apresentar o hospital a ser estudado, como é a logística hospitalar do local, como funciona a unitarização e a dispensação e os problemas a serem estudados. 


\section{Pesquisa de Campo}

Foi desenvolvida uma pesquisa dentro de um determinado hospital privado de grande porte, com o objetivo de realizar análises em relação aos insumos médicos hospitalares, especialmente os medicamentos.

A pesquisa tem como objetivo observar o funcionamento da logística do hospital e comparar com as tendências do setor. Para isso, o hospital disponibilizou informações internas, viabilizou a abertura de seus processos e tempo de seu pessoal para entrevistas com pessoas chaves dos processos e visitas técnicas dos processos internos.

\subsection{Metodologia e Desenho da Pesquisa}

A metodologia utilizada no estudo de caso possui uma abordagem qualitativa, de caráter exploratório e descritivo.

Para Neves (1996), a pesquisa qualitativa tem foco de interesse amplo direcionado ao longo do seu desenvolvimento, fazendo parte dela a obtenção de dados descritivos mediante o contato direto e interativo do pesquisador com a situação que é objeto de estudo. Faz parte do trabalho do pesquisador buscar entender os fenômenos, baseado na perspectiva das pessoas que vivem a situação estudada e a partir das observações interpretar e analisar os fatos estudados.

Minayo (1997) afirma que a abordagem para uma pesquisa qualitativa utiliza amostras pequenas e não aleatórias. Essas características são diferentes das pesquisas quantitativas devido à natureza das questões estudadas. Além disso, as características do tipo de pesquisa realizada não anulam a amostra, mas evidenciam o critério de seleção dos participantes da pesquisa.

Pesquisas exploratórias são aquelas nas quais os objetivos se concentram em conhecer melhor o objeto a ser investigado (Gil, 2007). Além disso, segundo Gil (2007), "pode-se dizer que estas pesquisas têm como objetivo principal o aprimoramento de ideias ou a descoberta de intuições". A escassez de literatura científica, sobre o tema cadeia interna hospitalar, faz com que a pesquisa desta 
dissertação seja exploratória. Para Yin (2007), a capacidade de descrever e avaliar os fatores que influenciam e geram impactos está ligada à exploração. As pesquisas descritivas são investigações que têm como finalidade exaurir as características do objeto proposto. O questionário e a observação sistemática são os métodos mais comuns de coleta de dados nesse tipo de pesquisa (Gil, 2007).

O método mais adequado para a realização da pesquisa proposta é o estudo de caso. Tal fato ocorre por conta do principal foco da pesquisa ser a exploração das características que tornam o setor hospitalar diferenciado. Sendo assim, podese avaliar, criteriosamente, todas as peculiaridades possíveis e levar em consideração a possibilidade de utilização de processos e ferramentas que já foram aplicadas em outros segmentos, além de hospitais considerados benchmark em processos logísticos.

Assim, a pesquisa, desta dissertação, foi realizada utilizando os seguintes métodos: entrevistas, observações in loco e análise de informações coletadas. Esses métodos foram escolhidos, pois consegue-se abranger todos os processos a serem estudados, tem-se contato com pessoas de diversas hierarquias e participante de todos os processos, além de poder detectar informações tendenciosas e/ou não condizentes com a realidade. Desse modo foram escolhidos gestores, funcionários e clientes do processo para as entrevistas.

Foi utilizado um questionário estruturado nas entrevistas que tinham como objetivo o entendimento da operação. Este formulário está localizado no Apêndice I. Além de direcionar as entrevistas, o questionário tinha como objetivo fazer perguntas importantes a respeito dos processos analisados.

Este mesmo questionário foi utilizado para todas as entrevistas realizadas independente do cargo do entrevistado. Entretanto, as perguntas eram direcionadas durante a entrevista, pois nem todos os entrevistados tinham condições de responder a todas as perguntas presentes.

Nesse estudo de caso focou-se em operações do hospital selecionado que envolviam materiais e medicamentos, mais especificamente as operações de unitarização e dispensação. O hospital disponibilizou dados de demanda dos medicamentos, além de permitir visitas à farmácia e a realização de entrevistas com os funcionários que participam dos processos que estão sendo analisados.

Dentre as pessoas entrevistadas duas foram de extrema importância para o conhecimento completo da operação. As entrevistas mais importantes foram 
realizadas com o Gestor da Farmácia e o Gestor do Estoque. Entretanto, foram entrevistados também funcionários que atuam diariamente nos processos estudados.

Durante uma visita acompanhou-se as operações de unitarização do medicamento e a operação de dispensação, nesta última incluindo a montagem dos kits que são enviados aos pacientes. Nessa observação o objetivo era acompanhar a forma como as atividades são realizadas, identificar problemas, gargalos e imprevistos que surgem ao longo do processo. Além disso, a compreensão do ponto de vista do funcionário que executa a tarefa é importante nesses casos, pois pode-se pensar em soluções que sejam fáceis de se implementar aumentando a produtividade, a eficiência e a eficácia do processo.

Desse modo, as análises sobre os processos estudados no hospital foram feitas baseadas nos dados recebidos, nas observações realizadas, nas entrevistas feitas e nas conversas com as pessoas que participam do processo. Os conhecimentos teóricos adquiridos durante o mestrado e a graduação também tiveram uma participação importante, assim como, as pesquisas para procurar boas práticas, em outros hospitais, de atividades envolvidas nos processos estudados. Com todos essas informações e conhecimentos foi possível propor melhorias baseadas nas análises feitas do processo atual.

As soluções propostas para os processos analisados serão apresentadas aos pontos focais desta pesquisa no hospital, Gestor da Farmácia e o Gestor do Estoque, para em seguida serem levadas a discussão aos gerentes executivos do hospital e, se possível, obter o aval para a implementação.

\subsection{Escolha da Organização}

O hospital escolhido para o estudo de caso vai ser identificado como Hospital X. Essa escolha foi feita por alguns critérios, bem como a abertura e disponibilidade por parte do local para a realização de visitas e entrevistas.

Os cinco critérios principais considerados foram: tipo de unidade, nível de atendimento, porte, esfera administrativa e natureza da organização.

Quanto ao tipo de unidade, optou-se pelos hospitais gerais, que facilitam a caracterização do segmento, representando a maioria dos hospitais brasileiros, por atender diversos tipos de pacientes. 
Alguns hospitais especializados, como os psiquiátricos, infantis e maternidades têm processos e suprimentos diferenciados, que não representariam a realidade generalizada do setor.

O nível de atendimento pode ser divido em quatro níveis: Primário, Secundário, Terciário e Apoio.

- Nível Primário - Consiste nas atividades de promoção, proteção e recuperação em nível ambulatorial.

- Nível Secundário - Consiste nas atividades assistenciais nas quatro especialidades médicas básicas (clínica médica, clínica cirúrgica, ginecoobstetrícia e pediatria). Além disso, há especialistas nesse tipo de unidade de hospitalar para as modalidades de atenção ambulatorial, internação, urgência e reabilitação.

- Nível Terciário - Possui maior capacidade para resolver os mais complexos problemas nas modalidades de atendimento ambulatorial, internação e de urgência.

- Nível de Apoio - Consiste em atividades de apoio diagnóstico como laboratório de patologia ou radiodiagnóstico. Os estabelecimentos que se encaixam nesse nível são unidades mistas, policlínicas e hospitais locais e regionais.

Este trabalho focou na seleção por locais que possuíam atendimento de nível terciário, pois buscou-se organizações que possuíam diversos tipos de atendimento, além de buscar práticas avançadas em tecnologia e processos que essas organizações possuem.

Em relação ao número de leitos, como já vimos anteriormente, os hospitais são classificados em categorias de porte. Para esse caso escolheu-se um hospital de porte grande, que vai de encontro ao objetivo de analisar unidades hospitalares com um certo nível de complexidade, visto que são nesses locais onde os processos e atividades têm a maior dificuldade no controle.

Hospitais privados geralmente têm uma receptividade maior aos pesquisadores que buscam um local para fazer os estudos de caso em relação aos hospitais públicos, apesar de imporem algumas restrições quanto a divulgação de dados reais (sem uma alteração dos valores) e nome da instituição. Como já vimos anteriormente, os hospitais privados podem ser divididos em duas categorias: com 
fins lucrativos e sem fins lucrativos (filantrópicos). Nos hospitais públicos a subdivisão é em administração direta e indireta. Nesse caso, optou-se por focar em um hospital de administração privada, devido a disponibilidade das informações, visitas e abertura de dados, além de possuir processos menos burocráticos em relação a um hospital da rede pública que possui peculiaridades em processos internos como a aquisição de medicamentos, que é regido por leis específicas (licitação).

Assim, além de um hospital de natureza particular, o hospital selecionado para a realização do estudo de caso é um hospital com fins lucrativos.

A Tabela 2, mostra as possíveis classificações dos critérios escolhidos acima e a classificação que o hospital selecionado tem em cada um dos critérios analisados.

Tabela 2: Critérios para a escolha do objeto de pesquisa. Fonte: Desenvolvido pelo autor

- Geral

Tipo de Unidade

- Especializado

Hospital Geral

- Primário

- Secundário

Nível de Atendimento

- Terciário

- Apoio

Nível de atendimento terciário

- Pequeno

- Médio

Porte

- Grande

- Extra

Hospital de porte grande

- Pública

Esfera Administrativa

- Privada

Hospital de esfera administrativa privada

- Pública

Natureza da

- Privada

Organização

- Filantrópica

Hospital de natureza privada 


\subsection{Hospital Selecionado}

A partir deste primeiro filtro, o hospital selecionado para a analise foi o Hospital X, cuja receptividade e disponibilidade mostraram-se apropriada para o desenvolvimento da pesquisa.

O Hospital X está localizado no Grande Rio, mais especificamente em Niterói, é relativamente novo, com apenas dois anos de existência, e é o segundo hospital de uma rede. Desde que foi criado, o hospital tem como público alvo a classe A da cidade e tem como objetivo minimizar as perdas de materiais e medicamentos e otimizar os seus processos internos.

O Hospital X é uma empresa familiar na qual duas famílias possuem o controle da unidade. Uma família é responsável pela parte clínica enquanto a outra gerencia a parte financeira. Estas famílias compõem a diretoria do hospital. No nível hierárquico seguinte, existe uma gerência executiva que toma as decisões do planejamento das operações juntamente com a diretoria.

O Hospital X tem 400 leitos dos quais apenas 247 estão em funcionamento, ou aproximadamente $62 \%$. O hospital possui 16 centros cirúrgicos, divididos em centros cirúrgicos geral e centro da mulher (neste ocorrem cirurgias de todos os tipos, especificamente para mulher, como plástica, partos entre outros), unidade coronariana, UTI, CTI, Emergência. Nesses locais, a demanda por materiais e medicamentos é considerável no hospital, especialmente nos 16 centros cirúrgicos onde a falta de um medicamento pode significar a morte de um paciente. Além disso, o hospital possui uma área para estoque dos itens, seis farmácias sendo uma central e cinco satélites que atendem locais específicas dos hospital (duas para atender os 16 centros cirúrgicos, uma para a UTI, uma para a unidade coronária, uma para atender a emergência e a farmácia central atende todos os leitos e andares do hospital). Assim conhecendo a quantidade de locais que são atendidos pelas farmácias do hospital conclui-se que é nas farmácias que ocorrem grande parte dos tratamentos dos insumos que passam pelo hospital.

É importante ressaltar também, que nos andares dos leitos, existe um pequeno espaço para que alguns poucos medicamentos sejam estocados. Esse estoque avançado ocorre nos casos de dificuldade no processo de unitarização ou dispensação daquele tipo de medicamento. 
As atividades de apoio logístico, na grande maioria dos serviços, é própria e sua infraestrutura encontram-se no interior do espaço hospitalar. Dentre as atividades próprias, podem-se destacar as seguintes: almoxarifado central, manutenção, farmácia central, cinco farmácias satélites, laboratório, central de material esterilizado e serviço de nutrição e dietética, esta última no hospital é dividida em duas, onde somente a nutrição via oral destinada a pacientes, acompanhantes e funcionários é própria. Os serviços terceirizados dentro do hospital compreendem nos serviços de lavanderia, alimentação para visitantes entre outros serviços que não tem relação com a atividade fim. 


\section{Estudo de Caso: Estado Atual}

Este capítulo dispõe sobre o funcionamento e a estrutura da farmácia central. Será abordado também o funcionamento de cada um dos processos analisados, Unitarização e Dispensação, do Hospital X. Além disso, serão analisadas oportunidades de melhoria que venham a existir nos processos para que sejam elaboradas soluções que venham a melhorar a qualidade do serviço, criando valor ao usuário e reduzindo os custos, se possível, dos processos em lida.

\subsection{Farmácia Central}

Antes de entender os processos de unitarização e dispensação que ocorrem no hospital, precisa-se conhecer a estrutura da farmácia central.

A farmácia central está localizada no quinto andar do hospital e possui locais de armazenamento para diversos tipos de medicamentos, um exemplo é a área de armazenamento de medicamentos refrigerados. Os medicamentos são armazenados em sua maioria unitarizados, em prateleiras móveis devidamente identificados, conforme pode ser observado na Figura 21.

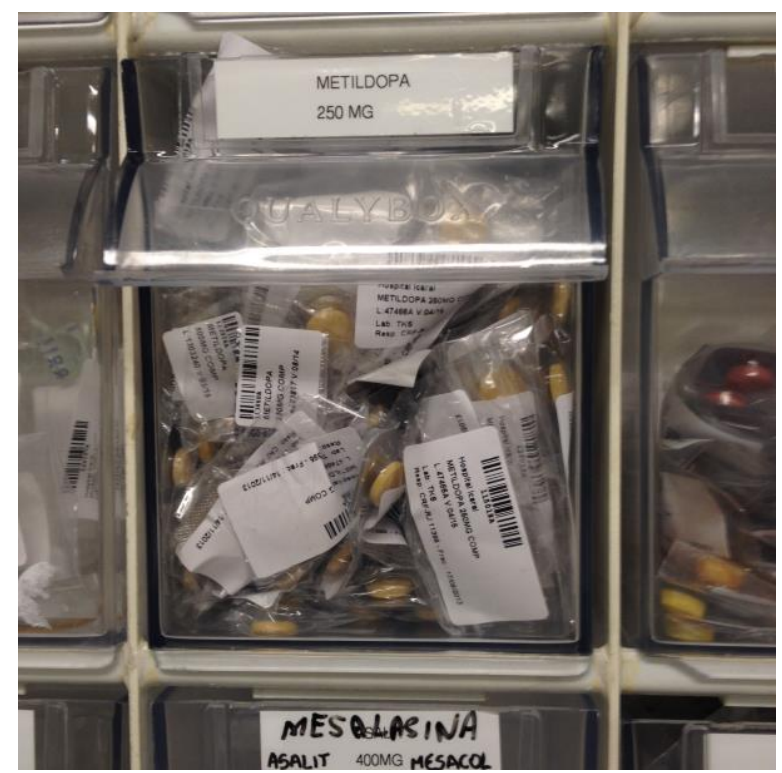

Figura 21: Medicamento unitarizado armazenado. Fonte: Imagem do local

A unitarização dos medicamentos ocorre em uma sala situada dentro da farmácia. Isso ocorre porque uma resolução de 11 de maio de 2006 da ANVISA 
obriga a presença de um farmacêutico responsável pelo processo que para ocorrer o fracionamento.

A dispensação dos medicamentos é realizada em uma sala em anexo à farmácia central. A posição estratégica do local de dispensação é fazer com que os kits preparados para serem enviados aos pacientes cheguem rapidamente aos funcionários que são responsáveis por levá-los aos pacientes.

Além desses dois processos, dentro da farmácia ainda ocorrem alguns processos administrativos, como a verificação das prescrições com o sistema e a gestão da farmácia central.

$\mathrm{Na}$ Figura 22 que está a seguir temos uma planta da farmácia central do Hospital X.

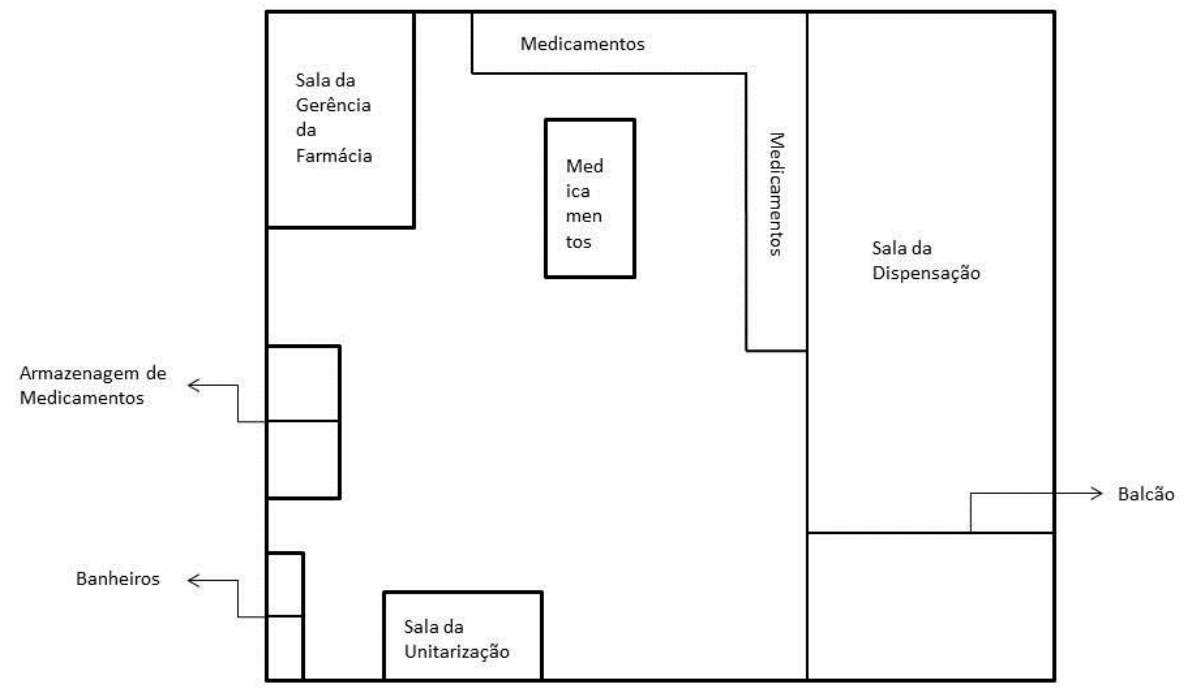

Figura 22: Planta da farmácia central. Fonte: Desenvolvida pelo autor

\subsection{Fluxo de Informação}

Compreendido a importância da Farmácia Central, é importante que se entenda também como funciona o fluxo de informações.

No Hospital X, existem diversos fluxo de informações, entretanto o mais importante para este trabalho é o que contém as informações sobre a necessidade de ressuprimento de estoque e a dispensação de medicamentos. Isso acontece 
porque essas informações são o ponto de início para os processos de unitarização e dispensação.

Desse modo, o fluxo de informação a ser analisado é o seguinte:

- Os leitos e áreas dos hospitais passam as prescrições para as farmácias com os remédios a serem ministrados aos pacientes;

- As farmácias informam a Farmácia Central a necessidade de algum medicamento que não está situado em seu estoque;

- A Farmácia Central detecta os medicamentos que estão abaixo ou próximo do nível mínimo de ressuprimento nas 6 farmácias do hospital;

- A Farmácia Central elabora um relatório com os medicamentos que devem ser repostos no estoque e em qual local e envia ao Estoque.

Esse fluxo de informação pode ser melhor observado pela Figura 23.

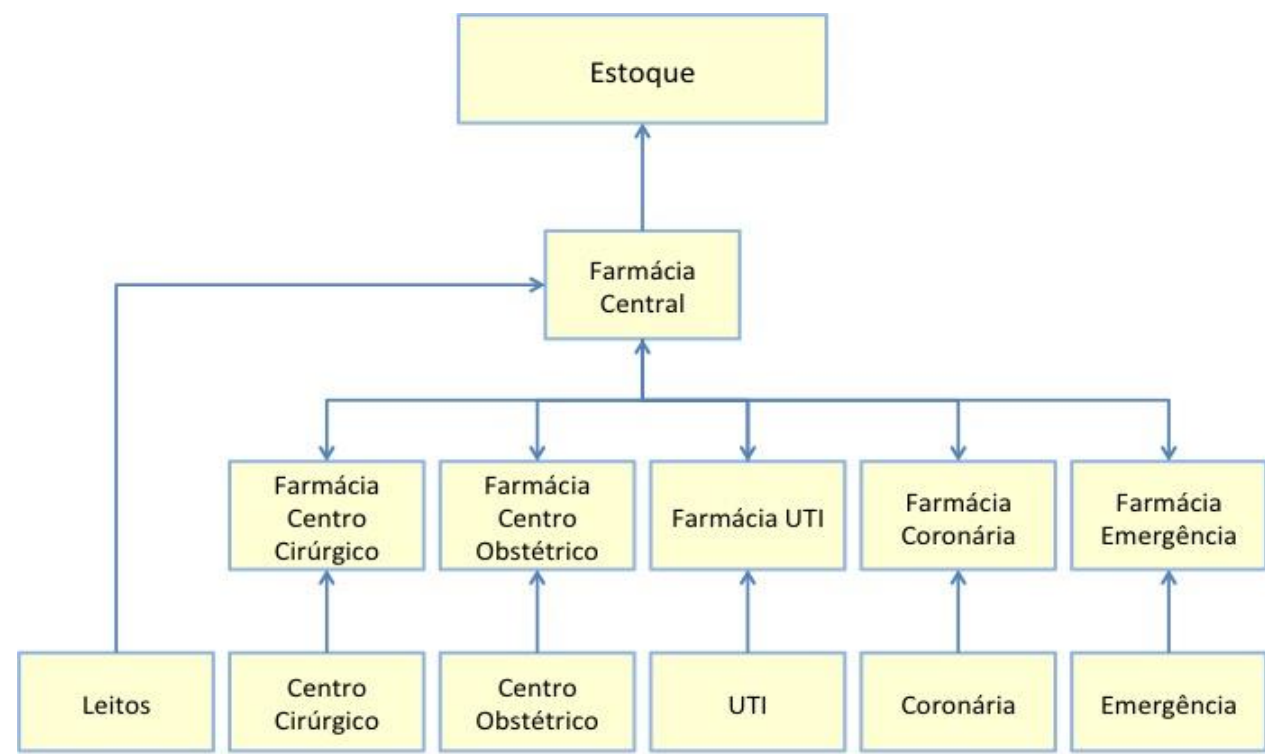

Figura 23: Fluxo de informações. Fonte: Desenvolvida pelo autor

Ao se analisar o fluxo de informações apresentado pode-se perceber quer há alguns pontos de melhoria, pois a Farmácia Central acaba sendo sobrecarregada com funções como o controle do estoque das outras farmácias.

Desse modo, percebe-se que o fluxo de informações pode ser melhorado de modo que ele fique otimizado e mais simples. 


\subsection{Unitarização}

No processo de fracionamento dos medicamentos no hospital, duas áreas estão amplamente envolvidas, a Gestão do Estoque e a Gestão da Farmácia.

Duas áreas estão envolvidas no processo de unitarização:

- O Estoque faz a separação dos itens de acordo com o relatório enviado pela farmácia;

- Ocorre a transferência dos itens do estoque para a Farmácia Central onde estes serão unitarizados;

- Os medicamentos são fracionados seguindo a política de reposição/fracionamento definida pelo hospital;

- Após o fracionamento, os medicamentos são enviados para as farmácias onde foi detectado que o nível de estoque está abaixo ou próximo do nível mínimo.

Após o mapeamento do processo de fracionamento, foi feita a análise da política de reposição/fracionamento do hospital.

A política de reposição de estoque tem um funcionamento um pouco singular. Isso se deve ao fato da Farmácia Central não atuar como um centro de distribuição, fazendo o ressuprimento das farmácias satélites. Ou seja, toda a vez que uma farmácia tem um medicamento que atingiu ou está abaixo do estoque mínimo, é necessário que a gestão do estoque envie o medicamento para a Farmácia Central para que este seja unitarizado e em seguida, enviado ao seu local de destino. Pode-se entender melhor o funcionamento da reposição de estoque através da Figura 24. 


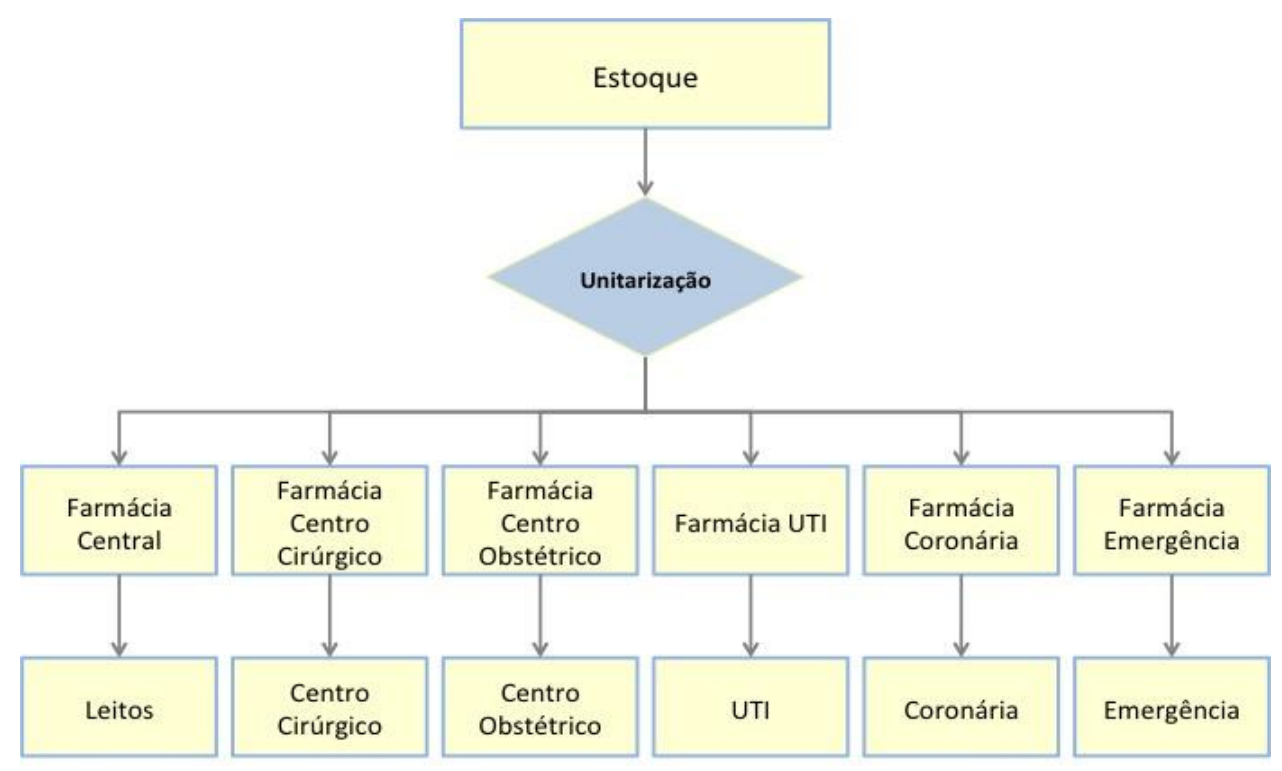

\section{$\longrightarrow$ Fluxo de Medicamentos}

Figura 24: Política de reposição de estoque. Fonte: Desenvolvida pelo autor

Essa política de reposição de estoque acaba afetando a forma como os medicamentos são fracionados. Isso porque como não existe uma distinção entre as farmácias central e satélite, ou seja, não existe uma farmácia atuando como um centro de distribuição, o fracionamento não pode ser realizado para uma única farmácia.

Assim de acordo com a política de fracionamento do Hospital X, os medicamentos são fracionados por farmácia, que atendem os determinados locais do hospital, seguindo a seguinte ordem:

1. Centro Cirúrgico;

2. Centro Obstétrico;

3. UTI;

4. Emergência;

5. Coronária (quando ocorre a unitarização para este local);

6. Farmácia Central.

Além disso, os medicamentos também são fracionados por tipo na seguinte sequencia:

1. Ampolas;

2. Frascos Ampolas;

3. Comprimidos. 
Os medicamentos líquidos e as pomadas por sua vez não possuem unitarização, o que leva aos gestores do estoque e da farmácia a enviarem esses tipos de medicamentos duas vezes por semana para o andar, gerando um estoque avançado desse tipo de medicamento nos andares.

A política de reposição de estoque e fracionamento do hospital não segue uma lógica de maximizar a utilização da máquina de unitarização. Isso acontece porque o processo de unitarização do hospital é feito de uma maneira onde a ordem dos medicamentos está definida, entretanto essa ordem tem que ser repetida 5 vezes pois os medicamentos são fracionados também por farmácia.

É importante observar também que, durante as entrevistas os funcionários envolvidos com o processo relataram que um dos grandes problemas que eles possuem é a má utilização da máquina.

Além disso, o hospital não realiza a unitarização de medicamentos líquidos e pomadas, os custos devido às perdas que ocorrem nesses medicamentos são grandes, podendo se afirmar através da observação em loco e das entrevistas realizadas.

Assim, com tudo que foi observado durante as entrevistas e as visitas ao hospital, foi possível fazer um diagnóstico da operação e identificar pontos que precisam ser melhorados para que se possa melhorar a cadeia de suprimentos e criar valor para o paciente. Os pontos de melhorias identificados foram:

1. Política de reposição de estoque

No Hospital X, conforme dito anteriormente, as farmácias, inclusive a Farmácia Central, atendem a um determinado local do hospital, isso inclui também a farmácia central. No caso desta, a diretoria impôs que ela atenda preferencialmente os leitos e evite atuar como um centro de distribuição. Essa determinação impede que a farmácia central faça a reposição do estoque das outras farmácias do hospital. Tal tarefa fica a cargo da gestão de estoque e da gestão da farmácia.

2. Revisão do processo de unitarização

Esse processo de unitarização é bastante afetado pela política de reposição de estoque do hospital. Desse modo, a máquina de unitarização realiza setups repetidos o que pode levar a realizar até 15 setups em um mesmo dia.

3. Unitarização de medicamentos líquidos e pomadas 
O hospital ainda não possui uma política de unitarização de líquidos e pomadas. $\mathrm{O}$ fato de não ter essa atividade acaba implicando no desperdício desses medicamentos e gerando um estoque avançado desnecessário, pois os medicamentos são enviados duas vezes por semana para cada andar com leitos.

\subsection{Dispensação}

No hospital o processo de dispensação ocorre de duas maneiras distintas, de acordo com o local onde se encontra o paciente. Nesse trabalho iremos analisar os dois tipos de dispensação para entender as suas particularidades e similaridades e buscar prováveis pontos de melhoria.

\subsubsection{Dispensação para a UTI}

Como o nome já diz, a dispensação para a UTI se refere a todos os medicamentos que são enviados para os pacientes que se encontram na UTI. A dispensação acontece sempre para um período de $24 \mathrm{~h}$, sendo os medicamentos enviados em 3 conjuntos de horários de 12:00 até 12:00 do dia seguinte.

Neste processo, as prescrições são enviadas da UTI para a Farmácia Central diariamente através de um sistema. Os conjuntos de horários estão definidos a seguir:

- $\quad$ 12:00 até $18: 59-1^{\circ}$ horário;

- 19:00 até 06:59 - $2^{\circ}$ horário;

- 07:00 até $11: 59-3^{\circ}$ horário.

Desse modo, o processo de dispensação para a UTI ocorre da seguinte forma:

- A prescrição eletrônica é enviada para a Farmácia Central;

- É feito a separação dos medicamentos em uma bandeja que possui horários de 2 em 2 horas (ver Figura 25 para uma melhor visão da bandeja);

- Após todos os medicamentos serem separados na bandeja, os medicamentos são colocados em sacos transparentes de acordo com o respectivo horário, que está escrito no próprio saco (ver Figura 25 para uma melhor visão do saco); 
- Com os sacos devidamente preenchidos com os medicamentos e lacrados, estes são colocados em cestos de acordo com o local a ser enviado (ver Figura 25 para uma melhor visão do cesto);

- Entre 10:00 e 11:00, um funcionário responsável por levar os medicamentos ao local vai na farmácia, recolhe os medicamentos e os leva ao local de destino.

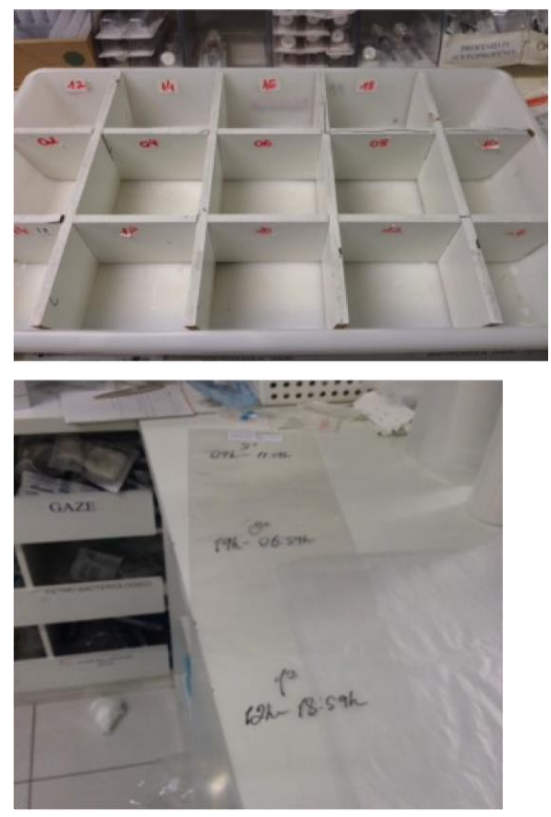

Saco utilizado para armazenar os medicamentos no processo de dispensação
Bandeja Utilizada na separação dos medicamentos no processo de dispensação

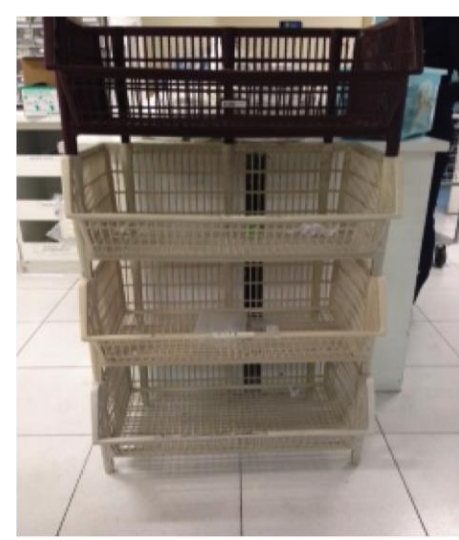

Cesto utilizado no processo de dispensação

Figura 25: Itens utilizados no processo de dispensação. Fonte: Desenvolvido pelo autor

Os sacos dos três horários são enviados ao mesmo tempo para o destino. Esse modo de fazer o envio dos medicamentos acaba gerando uma grande quantidade de devoluções, pois em alguns casos há uma troca na medicação, por parte do médico, e a nova medicação tem que ser ministrada antes do novo envio de medicamentos, assim os novos medicamentos são enviados como adiantamentos.

As ampolas de nebulização e ampolas de água não são enviadas à UTI de acordo com os horários pré-definidos. Estes medicamentos são enviados de acordo com a demanda. 


\subsubsection{Dispensação para os Leitos}

O processo de dispensação de medicamentos para os leitos, que engloba o $8^{\circ}$ andar do hospital até o $12^{\circ}$ andar, também é feito para 24 horas porém os medicamentos são enviados em apenas 2 conjuntos de horários 18:00 até às 18:00 do dia seguinte.

Os conjuntos de horários são os seguintes:

- $\quad 18: 00$ as $05: 59-1^{\circ}$ horário

- 06:00 as 17:59 - $2^{\circ}$ horário

Já o funcionamento do processo segue os mesmos passos do processo anterior. Entretanto para os $11^{\circ}$ e $12^{\circ}$ andares ocorre uma peculiaridade. Isso acontece porque os medicamentos que são enviados a esses andares são medicamentos controlados, devido ao fato desses dois últimos andares serem específicos para pacientes em estados mais graves. Assim a dispensação dos medicamentos dos dois horários não ocorre no mesmo momento, ou seja, para esses andares a dispensação é feita em cada um dos dois horários.

Além disso, devido a grande quantidade de medicamentos controlados enviados a esses andares, toda a vez que um remédio desse tipo é enviado ao andar, um farmacêutico leva o medicamento ao enfermeiro responsável que assina um papel confirmando o recebimento, evitando assim que remédios desse tipo sejam desviados do hospital.

Em algumas situações os enfermeiros também acabam por pedir um adiantamento de medicamentos, como no caso do processo de dispensação para a UTI. Por causa desse fato as devoluções são comuns.

Além das mudanças nos medicamentos, foi relatado pelos entrevistados participantes do processo na confecção dos kits de dispensação, que muitas das devoluções dos medicamentos são oriundas de erros nas prescrições enviadas pelos enfermeiros.

\subsubsection{Logística Reversa da Dispensação}

Conforme citado anteriormente, a devolução de medicamentos oriundos de erros nas prescrições médicas em muitas das vezes acaba sendo em grande quantidade. 
Porém um dos grandes problemas além desse erro, é o modo como os medicamentos são devolvidos. Isso porque ao devolver os remédios, os mesmos são apenas enviados a farmácia central para que esta possa reutilizá-los quando possível.

Desse modo, chegam medicamentos a Farmácia Central (local de devolução dos remédios não utilizados) sem estar em sua embalagem unitizada o que prejudica a reutilização do mesmo.

Assim percebe-se que, uma falta de controle na logística reversa da dispensação, também é responsável pela perda de medicamentos que poderiam ser enviados a outros pacientes.

\subsubsection{Diagnóstico da Dispensação}

Desse modo, de acordo com o que foi analisado no processo de dispensação, tanto para a UTI como para os leitos, e nas entrevistas podemos observar os pontos de melhorias no processo de dispensação que foram levantados:

1. Alteração na forma de dispensação dos medicamentos

No modelo de dispensação atual do hospital os medicamentos são enviados ao mesmo tempo para todos os horários. Conforme observado, esse modelo é responsável por boa parte das devoluções que ocorrem no hospital fazendo com que haja um retrabalho para recolocar os medicamentos devolvidos no estoque da Farmácia Central.

2. Mudança no formulário de prescrição

O formulário de prescrição foi mapeado como um ponto de melhoria pois muitas vezes os enfermeiros acabam por enviar o mesmo formulário porém com a data trocada. Outro fato importante é que os responsáveis por montar os kits reclamam muito das prescrições, pois no primeiro dia de internação deve ser sempre pedido um medicamento a mais devido ao horário da dispensação. Logo com a repetição das prescrições são enviados medicamentos em excesso, facilitando o desvio de remédios.

3. Implementação de um sistema para a logística reversa

O modelo atual de logística reversa permite que a quantidade de medicamentos perdidos seja alta devido a falta de controle do que é devolvido. 
Assim não é incomum que remédios sejam devolvidos sem estarem na embalagem unitarizada, ou então, os medicamentos não sejam nem devolvidos. 


\section{Estudo de Caso: Melhorias Propostas}

Após abordar a situação atual e fazer o diagnóstico da operação, abordando os pontos de melhoria dos processos de Unitarização e Dispensação do Hospital $\mathrm{X}$, nesse capítulo serão abordadas propostas de melhorias com o intuito de levar maior eficiência e eficácia aos processos.

\subsection{Fluxo de Informação}

O fluxo de informações do hospital foi analisado por completo em busca de uma solução que otimizasse as atividades. Buscou-se um fluxo aonde as informações chegassem até o estoque rapidamente sem prejudicar as outras atividades realizadas nas farmácias do hospital.

Desse modo nas atividades realizadas dentro do fluxo de informações entendeu-se que a Farmácia Central não deve controlar os níveis de estoque dos medicamentos com informações suportadas pelas farmácias satélites.

Ao se delegar essa atividade que no fluxo atual é da Farmácia Central entendeu-se que as farmácias satélites são mais capazes de fazer esse controle e podem adaptar, caso tenham a intenção, os níveis de estoque mínimo de acordo com as experiências dos funcionários que lá atuam.

Além disso, no novo fluxo de informação, que se encontra na Figura 26, a Farmácia Central diminui as suas responsabilidades e tem mais tempo para cuidar de atividades que sejam de sua competência. 


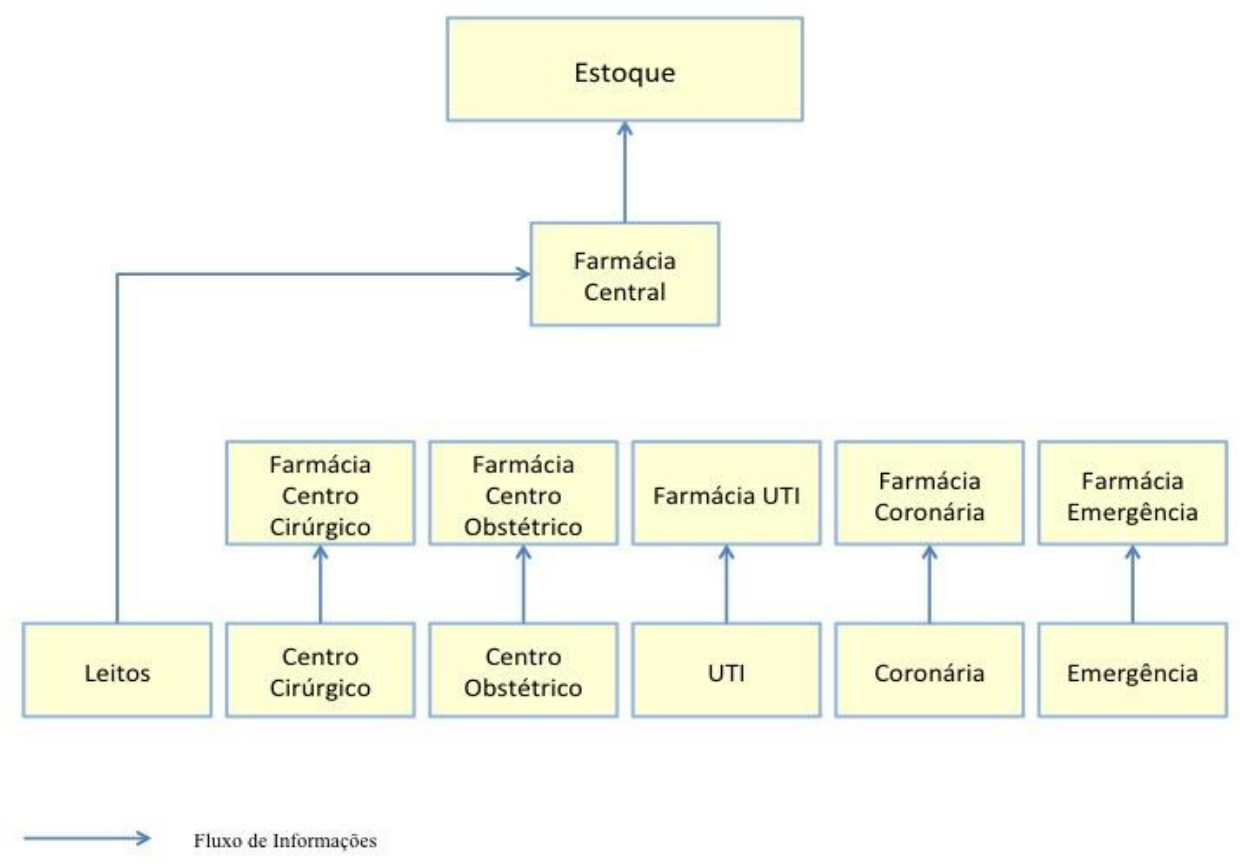

Figura 26: Novo fluxo de informações. Fonte: Desenvolvida pelo autor

\subsection{Unitarização}

Conforme foi analisado no capítulo anterior, o modelo atual de reposição de estoque é uma parte importante no processo de unitarização. Isso acontece pois a farmácia central não atua como um centro de distribuição, fazendo com que a unitarização dos medicamentos tenha que ocorrer para cada uma das farmácias do hospital.

Assim, após uma análise detalhada desse processo de ressuprimento, chegou-se a conclusão que deveria haver uma mudança neste processo, para que o processo de unitarização dos medicamentos possa ser alterado de modo a se tornar mais eficiente e eficaz.

Desse modo no novo processo de reposição de estoque, os medicamentos sairiam do estoque para o processo de fracionamento, passando em seguida para a farmácia central (que atuaria como um centro de distribuição). Com os medicamentos já unitarizados na farmácia central estes seriam distribuídos de acordo com a necessidade para as farmácias satélites.

Logo, a sugestão para o novo fluxograma do processo de ressuprimento é: 


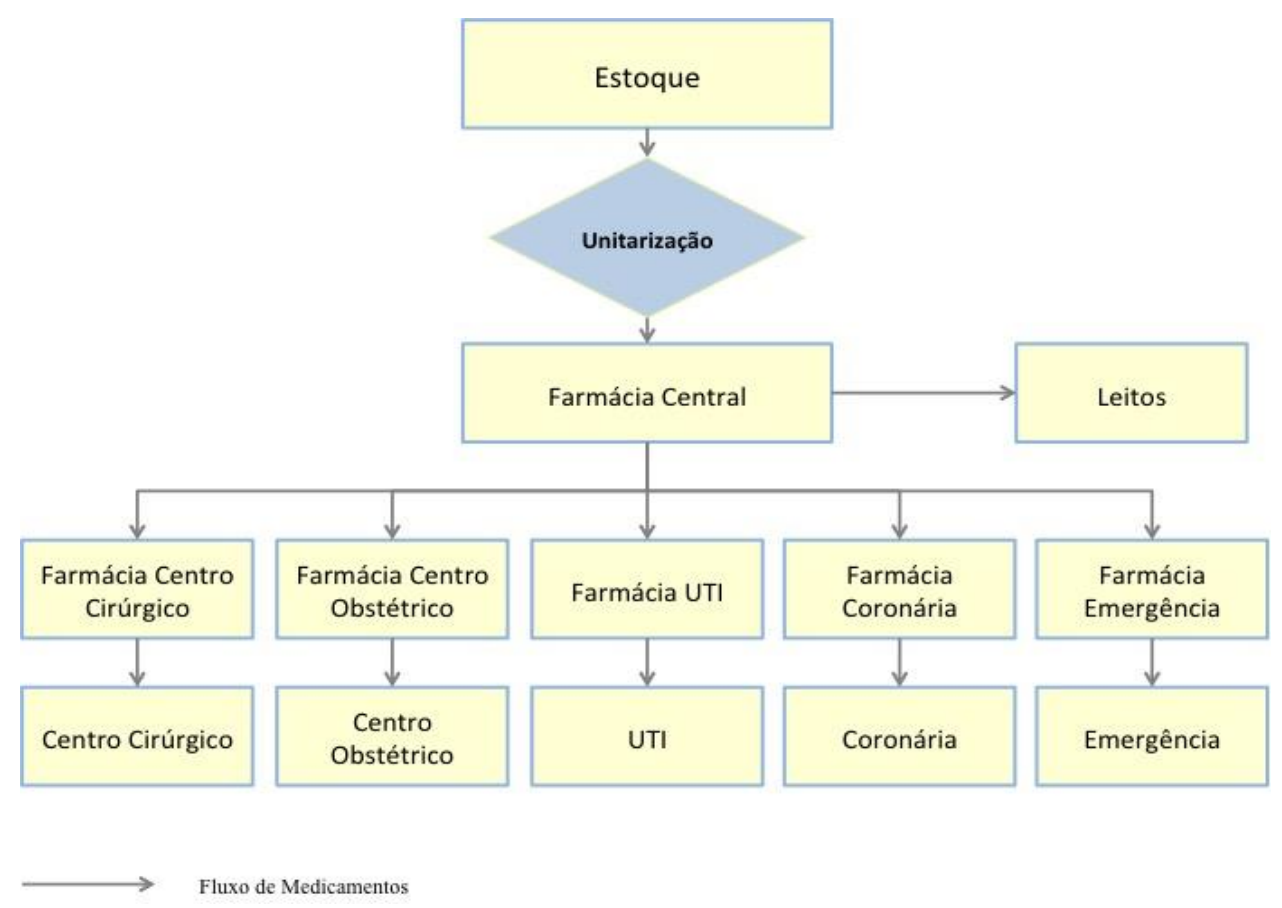

Figura 27: Novo processo de reposição de estoque. Fonte: Desenvolvida pelo autor

Esse novo processo apresenta algumas vantagens em relação ao estado atual, que são:

- A diminuição dos estoques nas farmácias satélites - Com a farmácia central atuando como um Centro de Distribuição e não mais exclusivamente para atender os leitos, os medicamentos estocados nas farmácias satélites podem ter seus estoques diminuídos, pois o estoque e o estoque de segurança serão centralizado na farmácia central fazendo com que a quantidade de medicamentos na farmácia satélite seja mínima.

- Diminuição do Lead Time - Por ter os estoques na farmácia central e estes já estarem unitizados, o tempo de ressuprimento, que já é baixo em um hospital, se torna menor ainda, já que não há a necessidade de esperar que o medicamento seja unitarizado para que o estoque avançado seja reposto.

- Melhoria no processo de unitarização dos medicamentos - Neste novo processo de unitarização seria necessário somente organizar o fracionamento por tipo de medicamento. Desse modo ocorreria uma diminuição de setups realizados, bem como se evitaria os setups dobrados.

Das três melhorias citadas anteriormente a que possui o maior impacto para o hospital é a melhoria no processo de unitarização dos medicamentos. Isso porque essa melhoria acaba sendo também solução para o problema da revisão do processo de unitarização. No caso desse ponto de melhoria encontrado no 
processo atual, percebeu-se o excesso de setups bem como a unitarização de um mesmo lote de medicamento várias vezes, destinado para locais diferentes.

Assim com a intenção de entender melhor os benefícios da melhoria no processo de unitarização dos medicamentos foi feito uma análise sobre os medicamentos fracionados no hospital. Precisa-se entender primeiramente as premissas utilizadas, bem como a metodologia aplicada para em seguida poder observar os resultados obtidos.

As premissas utilizadas para a realização das análises foram passadas pela gestão da farmácia do Hospital $\mathrm{X}$, além de definirem os tempos de setup da máquina são:

- Tempo de Setup da máquina por tipo de medicamento (ex.: ampola, frasco, comprimido): 5 minutos;

- Tempo de Setup da máquina por medicamento (ex.: trocar a etiqueta que será colada na embalagem unitizada): 1 minuto;

- Tempo Total necessário em um dia para fracionar os medicamentos: 7 horas a 8 horas.

Definida as premissas, fez-se um levantamento das informações sobre os medicamentos unitarizados na semana do dia 28 de abril de 2014 a dia 02 de maio de 2014. Depois de recebidas as informações do hospital, compilou-se os dados dos medicamentos em uma planilha Excel considerando os seguintes dados:

- Código;

- Descrição;

- Data do Fracionamento;

- Tipo;

- Lote;

- Validade;

- Quantidade;

- Destino.

Assim, com os dados consolidados, fez-se uma tabela dinâmica para descobrir a quantidade de setups realizados por tipo de medicamento e a quantidade de lotes fracionados considerando o estado atual do processo de unitarização. Desse modo, na tabela dinâmica considerou-se nas linhas o destino e 
o tipo de medicamento e nos valores a quantidade de tipos. Pode-se visualizar melhor essa informação na Tabela 3.

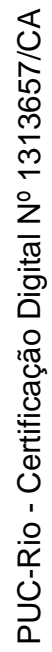




\begin{tabular}{|c|c|c|c|c|c|}
\hline Destino & Tipo & 28/abr & $29 / a b r$ & $30 / a b r$ & $02 / \mathrm{mai}$ \\
\hline \multirow{2}{*}{ Centro Cirurgico } & Ampola & 9 & 0 & 6 & 26 \\
\hline & Frasco & 6 & 0 & 6 & 15 \\
\hline \multirow[t]{3}{*}{ Centro Obstétrico } & Ampola & 2 & 0 & 6 & 5 \\
\hline & Frasco & 1 & 0 & 3 & 5 \\
\hline & Pote & 1 & 0 & 0 & 0 \\
\hline \multirow{3}{*}{ Emergência } & Comprimido & 0 & 0 & 2 & 0 \\
\hline & Gotas & 0 & 0 & 1 & 0 \\
\hline & Tubo & 2 & 0 & 0 & 2 \\
\hline \multirow{5}{*}{ Farmácia } & Ampola & 10 & 7 & 8 & 12 \\
\hline & Comprimido & 18 & 33 & 33 & 42 \\
\hline & Flaconete & 0 & 2 & 1 & 2 \\
\hline & Envelope & 1 & 0 & 1 & 0 \\
\hline & Pote & 0 & 0 & 1 & 0 \\
\hline \multirow[t]{4}{*}{ UTI } & Ampola & 0 & 0 & 4 & 4 \\
\hline & Comprimido & 0 & 0 & 0 & 1 \\
\hline & Tubo & 1 & 0 & 2 & 0 \\
\hline & Frasco & 3 & 0 & 0 & 3 \\
\hline
\end{tabular}


Com os dados apresentados na tabela, foi possível descobrir quantos lotes de medicamentos e de quais tipos tiveram como destino cada uma das farmácias do hospital. Entretanto, como se pode observar no Capítulo 5, os únicos tipos de medicamentos fracionados são os Comprimidos, os Frascos e as Ampolas. Desse modo, quando foi calculado a quantidade de setups por tipos de medicamentos, só foram considerados esses três tipos de medicamentos.

Para calcular o tempo de setup por lotes, os outros tipos de remédios também foram considerados, isso porque, apesar de não serem fracionados nas máquinas, os medicamentos recebem a etiqueta que é colocada nas embalagens. Logo eles também têm um tempo de setup para preparar essas etiquetas.

Sendo assim, para calcular o tempo de setup em minutos multiplicou-se a quantidade de tipo de medicamentos pelo tempo de setup por tipo de medicamento. O mesmo raciocínio é também utilizado para o cálculo do tempo de setup por lotes de medicamentos. Com essas informações chegou-se ao tempo gasto com o setup da máquina de fracionamento. Os valores estão explicitados na Tabela 4. 
Tabela 4: Tabela de setups e tempo por tipos e quantidades para o processo atual. Fonte: Desenvolvido pelo autor

\begin{tabular}{|c|c|c|c|c|c|}
\hline \multicolumn{6}{|c|}{ Estado Atual da Unitarizacão do Hospital } \\
\hline Data & Local & Tipos de & Tempo de Setup & Quantidade & Tempo Setup Lotes \\
\hline & & Medicamentos & Medicamentos (minutos) & de Lotes & (minutos) \\
\hline \multirow{5}{*}{$28 / 04$} & Centro Cirurgico & 2 & 10 & 18 & 18 \\
\hline & Centro & 2 & 10 & 4 & 4 \\
\hline & Emergência & 2 & 10 & 9 & 9 \\
\hline & Farmácia & 3 & 15 & 49 & 49 \\
\hline & Total & 12 & 60 & 84 & 84 \\
\hline \multirow{6}{*}{ 29/04 } & Centro Cirurgico & 2 & 10 & 0 & 0 \\
\hline & Centro & 2 & 10 & 0 & 0 \\
\hline & Emergência & 2 & 10 & 0 & 0 \\
\hline & Farmácia & 3 & 15 & 69 & 69 \\
\hline & UTI & 3 & 15 & 0 & 0 \\
\hline & Total & 12 & 60 & 69 & 69 \\
\hline \multirow{5}{*}{$30 / 04$} & Centro Cirurgico & 2 & 10 & 14 & 14 \\
\hline & Emergência & 2 & 10 & 15 & 15 \\
\hline & Farmácia & 3 & 15 & 66 & 66 \\
\hline & UTI & 3 & 15 & 6 & 6 \\
\hline & Total & 12 & 60 & 110 & 110 \\
\hline \multirow{6}{*}{$02 / 05$} & Centro Cirurgico & 2 & 10 & 26 & 26 \\
\hline & Centro & 2 & 10 & 42 & 42 \\
\hline & Emergência & 2 & 10 & 10 & 10 \\
\hline & Farmácia & 3 & 15 & 11 & 11 \\
\hline & UTI & 3 & 15 & 97 & 97 \\
\hline & Total & 12 & 60 & 186 & 186 \\
\hline Semana & Total & 48 & 240 & 449 & 449 \\
\hline
\end{tabular}


Ao se observar os valores totais da semana na Tabela 4, percebe-se que o tempo semanal de setup da máquina para o processo no atual sistema de utilização, é a soma do tempo total de setup por tipo de medicamento mais o tempo total de setup por lotes. Logo o tempo gasto semanalmente com setup é de 689 minutos ou 11 horas e 30 minutos.

Sabendo que o tempo total gasto para fracionar os medicamentos é de 7 a 8 horas por dia, ou seja um dia inteiro de trabalho. Assim o tempo gasto com setup na semana, atualmente é aproximadamente um dia e meio do tempo total de fracionamento.

Para entender qual seria o tempo gasto com o setup da máquina se o Hospital $\mathrm{X}$ adotasse o processo de unitarização proposto, primeiro temos que saber a quantidade de setups a serem feitos. Para isso, fez-se uma tabela dinâmica onde na linha foi considerado o tipo de medicamento e nos valores a quantidade de lotes para aquele tipo. A informação se encontra na Tabela 5.

Tabela 5: Tabela de quantidade de medicamentos unitarizados por tipo. Fonte: Desenvolvido pelo autor

\begin{tabular}{cc}
\hline Tipo & Quantidade de Lotes \\
\hline Ampola & 96 \\
Comprimido & 128 \\
Flaconete & 5 \\
Frasco & 124 \\
Gotas & 4 \\
Seringa & 13 \\
Tubo & 22 \\
Envelope & 2 \\
Pote & 2 \\
\hline
\end{tabular}

Com as informações obtidas na Tabela 5 é possível, juntamente com as premissas, calcular os novos tempos de setup. Assim foi calculado os tempos de setup da máquina para o processo de unitarização proposto. Os tempos estão explícitos na Tabela 6. 


\begin{tabular}{|c|c|c|c|c|c|}
\hline & \multirow[b]{2}{*}{ Tipos } & \multicolumn{3}{|c|}{ Estado Proposto da Unitarização do Hospital } & \multirow{2}{*}{$\begin{array}{l}\text { Tempo Setup } \\
\text { Lotes (minutos) }\end{array}$} \\
\hline Data & & Quantidade de Tipos & Tempo de SetUp & Quantidade de & \\
\hline \multirow[t]{9}{*}{$28 / 04$} & Ampola & 1 & 5 & 22 & 22 \\
\hline & Comprimido & 1 & 5 & 18 & 18 \\
\hline & Flaconete & 0 & 0 & 0 & 0 \\
\hline & Gotas & 0 & 0 & 0 & 0 \\
\hline & Seringa & 0 & 0 & 1 & 1 \\
\hline & Tubo & 0 & 0 & 8 & 8 \\
\hline & Envelope & 0 & 0 & 1 & 1 \\
\hline & Pote & 0 & 0 & 1 & 1 \\
\hline & Total & 3 & 15 & 80 & 80 \\
\hline \multirow{6}{*}{$29 / 04$} & Gotas & 0 & 0 & 1 & 1 \\
\hline & Seringa & 0 & 0 & 7 & 7 \\
\hline & Tubo & 0 & 0 & 3 & 3 \\
\hline & Envelope & 0 & 0 & 0 & 0 \\
\hline & Pote & 0 & 0 & 0 & 0 \\
\hline & Total & 3 & 15 & 69 & 69 \\
\hline \multirow[t]{2}{*}{$30 / 04$} & Ampola & 1 & 5 & 21 & 21 \\
\hline & Comprimido & 1 & 5 & 34 & 34 \\
\hline
\end{tabular}




\begin{tabular}{|c|c|c|c|c|c|}
\hline & Flaconete & 0 & 0 & 1 & 1 \\
\hline & Frasco & 1 & 5 & 30 & 30 \\
\hline & Gotas & 0 & 0 & 2 & 2 \\
\hline & Seringa & 0 & 0 & 0 & 0 \\
\hline & Tubo & 0 & 0 & 5 & 5 \\
\hline & Envelope & 0 & 0 & 1 & 1 \\
\hline & Pote & 0 & 0 & 1 & 1 \\
\hline & Total & 3 & 15 & 95 & 95 \\
\hline \multirow[t]{10}{*}{$02 / 05$} & Ampola & 1 & 5 & 46 & 46 \\
\hline & Comprimido & 1 & 5 & 43 & 43 \\
\hline & Flaconete & 0 & 0 & 2 & 2 \\
\hline & Frasco & 1 & 5 & 49 & 49 \\
\hline & Gotas & 0 & 0 & 1 & 1 \\
\hline & Seringa & 0 & 0 & 5 & 5 \\
\hline & Tubo & 0 & 0 & 6 & 6 \\
\hline & Envelope & 0 & 0 & 0 & 0 \\
\hline & Pote & 0 & 0 & 0 & 0 \\
\hline & Total & 3 & 15 & 152 & 152 \\
\hline Semana & Total & 12 & 60 & 396 & 396 \\
\hline
\end{tabular}


Na Tabela 6, pode-se observar os valores de setup por tipo de medicamento e por lotes (as fórmulas utilizadas para calcular os tempos foram as mesmas do cálculo para o processo atual). No processo proposto o tempo total gasto com o setup da máquina foi de 456 minutos ou 7 horas e 36 minutos.

Ao analisar os tempos de setup tanto por tipos de medicamentos, quanto por lotes e o tempo total pode-se perceber algumas diferenças do processo proposto em relação ao processo atual de fracionamento. As diferenças são as seguintes:

- A diminuição da quantidade de setups realizados, por tipo de medicamento, de 48 para 12: Essa queda na quantidade de setups, leva a uma economia de 180 minutos no tempo total de setups fazendo com que a redução percentual no tempo de setups por tipos de medicamentos seja de aproximadamente $75 \%$.

- A diminuição da quantidade de setups, por lotes, realizados de 449 para 396: Esse ganho do novo modelo de processo de unitarização resultou numa economia de 53 minutos o que acarreta em uma diminuição percentual de aproximadamente $12 \%$ nesse setup.

- A redução do tempo total de setup no processo de 11 horas e 30 minutos para 7 horas e 36 minutos: $O$ ganho de tempo relativo ao tempo total de setup é de 3 horas e 54 minutos ou $49 \%$ de diminuição no tempo.

Percebe-se nos resultados acima que o grande ganho deste novo modelo de unitarização é em relação à quantidade total de setups por tipo de medicamento, devido a sua redução de $75 \%$ no tempo.

Contudo, apesar de parecer inexpressivo em um primeiro momento, a diminuição de setups por lotes de medicamentos pode vir a ser um ganho importante neste processo. Essa afirmação se deve ao fato de que com o modelo atual de fracionamento e reposição de estoque muitas das vezes o mesmo medicamento do mesmo lote é fracionado mais de uma vez para farmácias distintas dentro do hospital.

Com o novo modelo esse tempo de setup dobrado tende a diminuir visto que a centralização do estoque na farmácia central irá fazer com que não haja a necessidade de fracionar medicamentos para diversos locais. Sendo assim só haveria um local para o qual os medicamentos teriam que ser fracionados, evitando um setup dobrado da máquina. Além disso, quanto mais medicamentos 
tiverem que ser fracionados para diferentes farmácias dentro da unidade hospitalar, maior será o ganho deste processo.

Há também ganhos que não são visualizados tão facilmente quanto os citados anteriormente, mas também são importantes de se ressaltar quando se adota os novos processos de reposição de estoque e unitarização de medicamentos. Estes ganhos estão listados a seguir:

- Diminuição do tempo de lead-time para a reposição de estoque: Apesar de já possuir um lead-time baixo, pois o estoque já se encontra dentro do hospital, nos novos processos o tempo para a reposição do estoque nas farmácias satélites tende a ser ainda menor. Isso se deve ao fato do estoque passar a ser centralizado, não havendo mais a necessidade de esperar que os medicamentos sejam unitarizados para depois serem enviados ao destino, visto que esse já se encontra pronto na farmácia central.

- Diminuição dos estoques das farmácias satélites: Este ganho está diretamente ligado à diminuição do tempo de lead-time. Essa relação é compreendida, pois com a redução do tempo de reposição dos medicamentos nas farmácias satélites pode-se diminuir a quantidade de medicamentos nos estoques avançados.

- Os funcionários responsáveis pelo processo de unitarização, neste novo modelo podem ser alocados em outras tarefas, pois ganharão algumas horas do dia com a redução do tempo de fracionamento.

- Diminuição dos erros no processo: Com este novo processo ocorre uma diminuição na possibilidade de se unitizar medicamentos sem a necessidade ou então fracionar menos do que o necessário. Esse fato ocorre, pois a unitarização é feita para um único local.

Feitas as análises da politica de reposição de estoque e da revisão do processo de unitarização, falta analisar o último ponto de melhoria identificado no capítulo 5, a unitarização de medicamentos líquidos e pomadas.

Conforme foi dito no capítulo anterior, o Hospital $\mathrm{X}$ ainda não possui nenhum método de fracionamento de líquidos e pomadas, o que acaba ocasionando desperdício de medicamentos uma vez que nem todos os remédios líquidos são completamente utilizados pelos pacientes. 
Baseado nessa informação foi pesquisada uma forma de se fazer a unitarização de medicamentos líquidos para que o Hospital X possa mesmo que de forma incipiente minimizar essas perdas. Desse modo foi feito uma pesquisa de benchmark no mercado com alguns hospitais para que se entendesse como é realizado esse fracionamento.

O método utilizado nos hospitais pesquisados é o da seringa Oralpack, esta pode ser de 3 tamanhos diferentes ( $3 \mathrm{ml}, 5 \mathrm{ml}$ ou 10ml) depende apenas da dose adotada pelo hospital. O fracionamento ocorre da seguinte forma:

- Separação do medicamento;

- Retirada do medicamento por meio de uma seringa do tipo Oralpack;

- A seringa é vedada com uma tampa que acompanha a mesma;

- A seringa cheia é etiquetada com as informações do remédio;

- A seringa é armazenada em local apropriado.

Nota-se que o processo de fracionamento de líquidos aplicado no mercado ainda é bastante manual. Sendo assim não é recomendado que se implemente o fracionamento para todos os medicamentos líquidos utilizados.

Para que haja uma diminuição dos gastos com esse tipo de medicamento, é recomendado que os remédios com o maior giro no estoque e o de maior valor sejam os únicos fracionados em um primeiro momento. Essa sugestão se deve ao fato de que ao unitarizar os medicamentos líquidos mais baratos, o tempo gasto e o custo para tal operação não se justifica devido ao valor do remédio.

Outro fator que afeta esse processo de fracionamento e suporta essa recomendação é o fato de que quando um medicamento líquido é fracionado sua validade cai em $75 \%$ do tempo. Desse modo não é interessante fracionar medicamentos que não tenham um giro alto.

Apesar da unitarização de medicamentos líquidos ainda ser feita de forma manual e incipiente, o que sugere grande perda de tempo e altos custos, esta ainda é uma das melhores formas de se fracionar medicamentos líquidos.

Uma forma de se melhorar este fracionamento seria através da compra de uma máquina mais moderna que realiza a unitarização tanto de medicamentos líquidos quanto de sólidos. Porém, esta solução não é viável no momento devido ao gasto recente com a máquina de fracionamento atual. 


\subsection{Dispensação}

Conforme observado no capítulo anterior, o processo de dispensação também apresenta alguns pontos de melhorias. Entretanto esses pontos demandam uma análise do processo um pouco mais profunda.

Baseado nas informações da revisão bibliográfica sobre diversos tipos de sistema de dispensação de medicamentos e no conhecimento do processo, algumas sugestões foram levantadas após a observação e as entrevistas realizadas com os funcionários atuantes.

Para o problema da alteração do processo de dispensação foi pensado um processo, em que os medicamentos só fossem enviados aos leitos momentos antes de serem administrados. Nesse sistema, que é o SDMDU (Sistema de Distribuição de Medicamentos por Dose Unitária), a principal vantagem seria a redução do número de devoluções que seriam gerados por mudança de medicamentos por partes dos médicos.

Entretanto, há uma grande necessidade de mão-de-obra em todos os momentos do dia. Essa demanda por mão de obra se deve ao fato de ocorrer dispensação praticamente a todos os momentos do dia.

Esse sistema, porém, acaba se tornando inviável para o Hospital X devido a necessidade de uma maior quantidade de mão de obra no turno da noite. Pois, com uma dispensação unitária haverá uma carga extra de trabalho a noite para preparar e levar os medicamentos aos leitos dos pacientes. Assim essa mão de obra extra não é viável no momento.

Outro ponto de melhoria levantado é a mudança no formulário de prescrição. Ao observar mais atentamente os fatores que levam a este problema, entendeu-se que o formulário de prescrição deve ser alterado de modo a facilitar o seu preenchimento.

Essa mudança deve ocorrer, pois é necessário identificar através do formulário quando o paciente deu entrada no hospital para saber-se quando estão sendo pedidos medicamentos a mais, evitando assim as devoluções para a farmácia. Porém, essa mudança deve ser feita em conjunto pela enfermagem, que é a área responsável pelo preenchimento, juntamente com a TI.

A necessidade prioritária neste caso, para tentar reduzir o número de erros nas prescrições em curto prazo, seria um treinamento dos profissionais da 
enfermagem explicando como deve ser feito o preenchimento. Além desse treinamento, deve ser feito um monitoramento dessa atividade para que seja garantido que as práticas adotadas para o preenchimento deste formulário sejam seguidas.

O último ponto de melhoria levantado no capítulo 5 , foi a implementação de um sistema para a logística reversa. Essa sugestão se deve ao fato de não haver uma logística responsável pelo recolhimento dos medicamentos que não são utilizados e a falta de um controle mais rígido dos medicamentos que são devolvidos.

Desse modo é importante que a diretoria do hospital, juntamente com os responsáveis pelo processo de devolução dos medicamentos, chegue a um fluxograma detalhado de um novo processo de logística reversa que minimizaria os problemas do processo atual.

Além disso, com a criação de um sistema para apoiar esse processo, haveria um controle maior desta operação e seria possível a comparação da lista de medicamentos enviados ao setor. Assim, o sistema, em conjunto com o fluxograma do novo processo de logística reversa, iria ser benéfico para o processo evitando que medicamentos sejam considerados inutilizados e/ou sumam dos hospitais. 


\section{Conclusão}

Este trabalho buscou entender e analisar a importância da logística hospitalar, bem como entender qual o grau de maturidade em que se encontra.

Os hospitais já perceberam que ter uma logística interna é fundamental para diminuir os gastos que vem crescendo nos últimos anos, para agregar valor ao paciente e tornarem-se mais eficientes na utilização dos recursos, criando competitividade frente aos concorrentes.

Barbieri e Machline (2006) afirmam que quanto maior a capacidade da farmácia de uma organização hospitalar em administrar de maneira adequada seus produtos, maior será a qualidade dos serviços a serem oferecidos aos clientes com baixos custos operacionais.

Dentro dos crescentes gastos, os insumos hospitalares são os segundos mais representativos e os mesmos correspondem a maior parte da receita de um hospital. Para Klügl et al (1999) o emprego racional de medicamentos, incluindo a padronização, pode ser retratado em uma redução dos custos das organizações hospitalares. Assim, por causa da importância e por não ser core business do hospital, a logística desse tipo de material representa uma grande oportunidade de redução de custos e otimização de processo.

Entretanto a análise desses processos não é simples, devido a sua complexidade somada as peculiaridades do setor hospitalar e as falhas que ocorrem nas unidades hospitalares. Pode-se dizer que o hospital estudado neste trabalho não é diferente da realidade hospitalar no país.

Todos esses fatores, citados anteriormente, foram levados em conta na análise dos processos da logística interna de medicamentos para que pudesse mapear as falhas e os pontos de melhoria da unitarização e da dispensação.

Desse modo, os dois processos analisados no Capítulo 5 tiveram o seus pontos de melhorias levantados e buscou-se entender quais os impactos na unitarização e na dispensação. Com o melhor entendimento do que deveria ser melhorado nos processos buscaram-se soluções para aperfeiçoar tanto a unitarização quanto a dispensação. 
As melhorias propostas foram influenciadas por outros segmentos do mercado onde a logística é mais avançada do que no segmento hospitalar. Essa aplicação de modelos e processos de outros setores é mais explicita na revisão do processo de reposição do estoque do hospital onde foi aplicado esse conhecimento de outras áreas.

Além disso, foram feitas análises sobre dados dos processos atuais para que estes valores pudessem ser comparados com os dados das análises sobre o modelo de processos propostos. Através dessas comparações foi possível observar as melhorias significativas que tem grande impacto no trabalho das pessoas responsáveis por ambos os processos.

Desta forma, pudemos ver que a organização hospitalar em questão já começa a se mover ao abrir as portas para este estudo. Os responsáveis pela farmácia, setor mais impactado pelo estudo, bem como os responsáveis pelo estoque irão levar as análises feitas juntamente com os resultados para a direção do hospital com o objetivo de garantir a mudança no processo.

A profissionalização de algumas atividades, além da implantação de ferramentas de apoio e tecnologias de última geração, teve início nos principais hospitais privados do mundo e, mais tarde, brasileiros. A tendência é que este movimento se intensifique no país nos próximos anos, melhorando a qualidade no atendimento e garantindo maior segurança ao paciente.

Apesar de esse trabalho ter feito uma análise profunda de dois processos importantes na logística interna hospitalar, ficou evidente que ainda há alguns pontos que precisam ser melhores estudados. Assim pode-se citar que algumas sugestões de trabalhos futuros são:

- Análise do processo de compra de medicamentos e materiais dos hospitais. A área de suprimentos nas empresas hoje é alvo de muito estudo em outros setores. Assim um estudo desse processo se mostra necessário, visto que o uso de metodologia e ferramentas do Strategic Sourcing podem reduzir consideravelmente os custos de uma empresa.

- Revisão do sistema de prescrição de medicamentos. O sistema é uma parte importante na logística do hospital pois é através dele que as enfermeiras fazem o pedido baseado no diagnóstico médico. Esse estudo mais detalhado possibilitaria uma redução nas devoluções e um formulário mais fácil de ser preenchido. 
- Análise entre o esforço para unitarizar o medicamento e o custo desse medicamento para o hospital. Nem todos os medicamentos precisam ser unitarizados, pois alguns possuem um custo tão pequeno para o hospital que o custo de unitarizá-lo acaba se tornando alto. Desse modo um estudo para saber quais os medicamentos necessitam ser fracionados e como classifica-los é importante. 


\section{Referências Bibliográficas}

ANTHONY R.N., Planning and Control Systems: A Framework for Analysis. Division of Research, Graduate School of Business Administration, Harvard University, 1965.

ANVISA. Guia para farmacêuticos de Medicamentos Fracionados. Brasil. 2006

APTEL, O.; POURJALALI, H., Improving activities and decreasing costs of logistics in hospitals: a comparasion of U. S. and French hospitals. The International Journal of Accounting, v.36, p.65-90, 2001.

AROZO, R., Monitoramento de desempenho na gestão de estoque. Centro de Estudos em Logística - CEL - COPPEAD - UFRJ, Rio de Janeiro, RJ, 2002.

ASHP., ASHP Technical Assistance Bulletin on Single Unit and Unit Dose Packages of Drugs - Appendix 7A. Drug Distribution and Control: DistributionTechnical Assistance Bulletins. 1985

AZEVEDO NETO, F. P. B., Gestão logística em saúde / Francisco de Paula Bueno de Azevedo Neto, Washington Luiz Mourão Silva, Vera Lucia Luiza. Florianópolis: Departamento de Ciências da Administração/ UFSC; [Brasília]: CAPES: UAB, 2010.96p.

BALlOU, R. H., Gerenciamento da cadeia de suprimentos. Planejamento, organização e logística empresarial. 4. ed. São Paulo: Bookman, 2001.

BARBIERI, J. C.; MACHLINE, C., Logística hospitalar: teoria e prática. São Paulo: Saraiva, 2006.

BOWERSOX, D. J.; CLOSS, D. J., Logística empresarial: o processo de integração da cadeia de suprimento. São Paulo, 2001: Atlas, 594p

BRASIL, Ministério da Saúde. Coordenação de Controle de Farmácia Hospitalar. Guia Básico para a Farmácia Hospitalar. Brasília, 1994. 174 p.

BUZZACOTT, J. A.; SHANTHIKUMAR, J. G., Safety stock versus safety time in MRP controlled production systems. Management Science, v. 40, n. 3, p. 1678-1689, 1994. 
CALAZANS, F., Centros de distribuição. Gazeta Mercantil: Agosto, 2001.

CAVALlinI, M. E.; BISSON, M. P., Farmácia hospitalar: um enfoque em sistemas de saúde. Barueri: Manole, 2002.

FALK, J. A., Gestão de Custos para Hospitais: Conceitos, Metodologias e Aplicações. São Paulo: Atlas, 2001. 232p.

FINOTTI, C. M. D. da C., Sistema de distribuição de medicamentos na farmácia hospitalar. Portal Educação. 29 out 2010.

FITZSIMMONS, J. A.; FITZSIMMONS, M. J., Administração de serviços: operações, estratégia e tecnologia da informação. 4. ed. Porto Alegre: Bookman, 2005.

FREITAS, A. R. de., Vigilância Sanitária na Farmácia Hospitalar: o Sistema de Distribuição de Medicamentos por Dose Unitária (SDMDU) em foco. Ministério da Saúde. Fundação Osvaldo Cruz. Escola Nacional de Saúde Pública Sergio Arouca. Curso de especialização em Vigilância Sanitária de Serviços de Saúde. Rio de Janeiro. 2004.

GIANNOCCARO, I.; PONTRANDOLFO, P., Aligning inventory managements systems to supply chain types. In: DIERDONCK, R; VEREECKE,A. (Eds). Operations management crossing borders and boundaries: the changing role of operations. Ghent, Belgium: Academic Press A Cientific Booksellers, 2000.

GIL, A. C., Como elaborar projetos de pesquisa. 4. ed. São Paulo: Atlas, 2007.

HANS, E.W.; VAN HOUDENHOVEN, M.; HULSHOF, P. J. H., A framework for health care planning and control. In International Series in Operations Research \& Management Science (HALL RW, Ed), pp 303-320, Vol. 168, 2012 A.

HANS, E. W.; KORTBEEK, N.; HULSHOF, P. J.H.; BAKKER, P.J.M.; BOUCHERIE, R. J., Taxonomic classification of planning decisions in health care: a structured review of the state of the art in OR/MS. p 129-175, 2012 B.

HAUTANIEMI, P.; PIRTTILÄ, T., The choice of replenishment policies in an MRP environment. International Journal of Production Economics, v. 59, p. 8592, 1999.

INFANTE, M.; SANTOS, M. A. B., A Organização do Abastecimento do Hospital Público a partir da Cadeia Produtiva: Uma abordagem logística para área de saúde. Rio de Janeiro: Ciência e Saúde Coletiva, jul-ago, ano12, n.4, 945-954. 2007. 
JACOBI, M. A., How to unlock the benefits of MRP II and Just-in-Time: Hospital Material Management. Vol. 15 , pp.12-22. 1994.

KLÜGL, F. et al., Multi-agent simulation of diagnostic and logistic processes in hospitals. TU Ilmenau, Wirtschaftsinformatik 2, Arbeitsbericht, n. 14, p. 151159, jul. 1999.

LACERDA, L., Armazenagem estratégica: analisando novos conceitos. Centro de Estudos em Logística (CEL), COPPEAD/UFRJ, 2000.

LOTTEnBerg, C., O Setor de Saúde no Brasil. São Paulo: Atheneu, 21 de outubro de 2010.

MINAYO, M. C. S., Pesquisa social: teoria, método e criatividade. Rio de Janeiro: Editora Vozes, 1997.

MMWR - Morbidity and Mortality Weekly Report. Centers for Disease Control and Prevention. V. 55, n. 1, 2006.

NAIDU, A., Factors affecting patient satisfaction and healthcare quality. International Journal of Health Care Quality Assurance, v.22, n.4, p.366-381, 2009.

NAPAL, V.; GONZALÉZ, M.; FERRÁNDIZ, J. R., Dispensación com intervención previa del Farmacêutico: dosis unitárias. In: FALGAS BJ, DOMINGUEZ A, HURLÉ G, PLANTAS MCG, LECUMBERRI VN, MOLINA EV. Farmacia Hospitalaria. Spaña: SEFH. p. 389-414, 2002.

NEVES, L. J., Pesquisa Qualitativa - Características, Usos e Possibilidades. Caderno de Pesquisas em Administração, São Paulo, v.1, No 3, 2o semestre/1996.

PAES, R. A. L., Uma investigação sobre o uso da informação na cadeia interna de suprimentos em hospitais na cidade de São Paulo, 2009.

PIZZOLATO, N. D.; PINHO, A. R., A regionalização dos centros de distribuição como solução logística. Tecnologística, Ano VIII, n. 87, fev. 2003.

PORTELLA, A., Padronização e custos: uma questão de logística hospitalar, 2001.

PORTER, M.; TEISBERG, E. O., Redefining Health Care: Creating ValueBased Competition on Results. Boston: HBS Press, 2006. 
RAMANI, K. V., Managing hospital supplies: process reengineering at Gujarat Cancer Research Institute, India. Journal of Health Organization and Management, v. 20, n. 3, p. 218-226, 2006.

RODRIGUES, G. G.; PIZZOLATO, N. D., Centro de Distribuição: armazenagem estratégica. ENEGEP. Ouro Preto, MG, 2003

RIBEIRO, E., Dose Unitária: Sistema de Distribuição de Medicamentos em Hospitais. Revista de Administração de Empresas. São Paulo, 33(6):62-73. Nov./Dez. 1993.

SIPNASS. Programa Nacional de Avaliação dos Serviços de Saúde.

SLACK, N. et al., Administração da produção. 2. ed. São Paulo, 2002.

SLACK, N. et al., Gerenciamento de Operações e de Processos. São Paulo: Bookman, 2008.

SNABS. Coordenação de Assistência Médica e Hospitalar. Conceitos e Definições em Saúde. 1977.

VECINA NETO, G.; REINHARDT FILHO, W., Gestão de Recursos Materiais e de Medicamentos. Faculdade de Saúde Pública da Universidade de São Paulo. v12, São Paulo, 1998.

VRIES, J., The complex relationship between inventory control and organizational setting: Theory and practice. International Journal of Production Economics, v. 93-94, p. 273-284, 2004.

WANKE, P., Gestão de estoques. In: FLEURY, P.F.; FIGUEIREDO, K.; WANKE, P. (Org.). Logística empresarial. São Paulo: Atlas, 2000. p. 177-208. Coleção COPPEAD de Administração.

YIN, R. K., Estudo de Caso - Planejamento e Métodos. Porto Alegre: Bookman, 2007. 


\section{Apêndice I}

\section{Questionário de Visita Técnica Operação do Hospital}

Funcionamento Geral

1. Número de leitos do hospital.

2. Quais são os principais setores do hospital

3. Quantos atendimentos por mês/semana/dia? Por setor?

4. Qual setor consome mais insumos médico-hospitalares?

5. Qual setor onde mais ocorrem problemas de abastecimento? Onde mais ocorre falta? Operação menos previsível?

6. Como é o planejamento das operações do hospital? Quem participa desse processo?

Logística intra-hospitalar

7. Ciclo de Pedido

7.1. Onde surge a demanda? Quem faz o pedido? Médico? Enfermeiro? Quem são os clientes da farmácia Central? E das farmácias satélite?

\subsection{Como vem esse pedido (sistema)}

7.3. Quantos pedidos por semana/dia a farmácia central recebe?

7.4. Existe alguma medição de nível serviço? Algum indicador? Algum acordo de atendimento? Alguma programação de entregas? Políticas de estoques?

7.5. Como são tratadas as demandas urgentes? E quando falta o medicamento, o que e feito? Existe algum plano de contingência definido?

8. Rede intrahospitalar e Tamanho da Operação

8.1. Quantos pontos de demanda no hospital (número de farmácias satélite, leitos, andares, salas cirúrgicas)? Quantas Farmácias centrais? Armazém externo? 
8.2. Valor em estoque? Compras Anuais (\% do custo)?

9. Demanda

9.1. Quais são os principais itens de consumo (de maior giro) no Hospital? Outros insumos além de medicamentos e materiais médico-hospitalares são significativos?

9.2. Todos os itens vão para estoque? Como é definido o que vai para estoque e o que vai direto para despesa?

9.3. Quais são os tipos de demanda que influenciam/direcionam a forma organização da operação (salas de cirurgia, CTI, UTI, emergência, etc.)?

9.4. Qual o nível de planejamento/previsibilidade para cada tipo? Quais tipos são as operações mais previsíveis/de mais fácil antecipação?.

9.5. Onde a operação é mais crítica (risco de morte mais alto, demanda mais intensa, demanda menos previsível, etc.)?

9.6. Qual o nível de padronização da demanda (insumos padrão e não padrão)? Quem define a marca do remédio? Existem políticas de padronização?

9.7. Existe muita sazonalidade (inverno/verão, epidemias/surtos, etc.)?

10. Recebimento / Conferência

10.1. Quantas transações de entrada/recebimento por semana ou dia?

10.2. Como é processo de conferência? Ocorrem muitos erros no fornecimento (pedido versus nota fiscalversus entrega)? Algum indicador/medição? .

10.3. Quantos caminhões por dia/semana são recebidos? Quantas docas para recebimento? Docas com altura ajustável?

10.4. Existe algum gargalo no recebimento? Fila de caminhões, poucas docas, pouca área de recebimento/processo de conferência?

11. Armazenagem

11.1. Infraestrutura: Qual é a área total da Farmácia Central? Existem equipamentos de armazenagem?

11.2. Existem subdivisões (área climatizada, escura, normal, manipulação, picking, reserva, expedição e montagem de kits)?

11.3. Quais os itens que mais ocupam espaço no armazém? São críticos para operação? A falta deles pode causar mortes? 
11.4. Existe algum sistema apoiando essa operação? Localização dos insumos no sistema? Controle de validade? Controle de Giro?

\section{Fracionamento/Unitarização}

12.1. Em que situações/demandas é necessário o fracionamento dos remédios? É um processo recorrente/rotineiro?

12.2. Quais setores do hospital/tipos de atendimento requerem esse tipo serviço?

12.3. Quais são os principais insumos (pílulas, ampolas, líquidos, etc.) que necessitam de fracionamento? Quais são os que mais consomem tempo? Quais são os mais suscetíveis a erros? Quais são os mais arriscados?

12.4. Existe perda nesse processo?

12.5. Como é feito o controle do estoque pós-fracionamento? Existe alguma mudança de registro no ERP (identificação 1 a 1?)?

12.6. Como é feita a baixa dos insumos fracionados?

12.7. O processo é automático? Existe algum equipamento/ferramenta?

12.8. Há identificação por código de barra no fracionamento dos medicamentos? Existe algum outro método de identificação?

13. Montagem de Kits

13.1. Em quais operações/situações ocorrem montagens de kits (tipos de cirurgia)? Quais eventos definem uma montagem de kit?

13.2. Quem define o que os insumos (tipos e quantidade) de um kit? Algum manual?

13.3. Como é feito o controle do material que sai via kit? Processo de baixa? Existe algum procedimento/assinatura entre usuário do kit e farmácia acordando insumos utilizados?

13.4. Quantos kits são montados por semana/dia?

14. Expedição/Distribuição

14.1. Entrega a balcão? Domicílio? Quem busca? Quem entrega? Mensageiro que vai no local para entrega.

14.2. Existe algum equipamento para transporte de materiais? Transportados em caixas transparentes identificados

14.3. Como é o processo de baixa de estoque? Em que momento ocorre? 
14.4. Existe alguma programação fixa de entregas (janelas de expedição, faixas de horário, entregas por dia mais urgentes)?

14.5. Quantos pedidos de transferência/entrega por semana/dia?

14.6. Como é feito o controle das transferências internas para os estoques intermediários? Via sistema? Existem postos do ERP nesses pontos para baixa do estoque? 